Article

\title{
Noise Source Visualization for Small DC Motors Using Current Reference without a Reference Microphone
}

\author{
Yong Thung Cho \\ Division of Mechanical and Automotive Engineering, Kongju National University, ChunAn, \\ ChoongNam 31080, Korea; cho.yong@gmail.com; Tel.: +82-41-521-9277
}

Received: 11 May 2018; Accepted: 6 June 2018; Published: 9 June 2018

\begin{abstract}
Noise and vibration sources from small direct current (DC) motors should be clearly visualized for optimal design of low noise motors. For accurate visualization, relatively good reference measurements at optimal locations are required. For some very small motors, the optimal position for a stationary reference microphone may not be accessible during measurement. However, strategies for small motor noise visualization without using a reference microphone have been developed in this study. Only scanning microphones and current measurements of a small motor were used to visualize sound sources. Scanning microphone signals combined with current measurements were used as moving reference signals. Motor noise visualization results based on different moving reference locations have been estimated and reported. Consistent motor noise visualization results from motor current and different, moving reference locations for the major electro-magnetic force excitation frequencies have been shown. Furthermore, for frequencies with relatively low current amplitude, clear motor noise visualization results have been produced for a moving reference located at the center of the motor. Also, the relationship between motor noise and current has been shown, and motor noise has been reduced by connecting an optimal capacitor to the motor power input.
\end{abstract}

Keywords: motor noise visualization; micro motor; motor current; moving reference

\section{Introduction}

Various analytical and experimental efforts to design and manufacture low noise motors have been made. The electro-magnetic force and cogging torque of these motors has been actively analyzed [1-3], and noise radiating from structural and acoustical resonances was measured and matched through simulation [4]. The relationship between motor current and radiated noise was investigated both in simulation and by experiment [5]. To derive an optimal design for low noise motors, sources of motor noise and vibration should be accurately visualized. Such sources were clearly visualized for a small direct current (DC) motor, and the results were confirmed with structural excitation tests using an impact hammer and motor run-up tests for different motor rotational speeds [6]. For accurate visualization of motor noise sources, relatively good reference measurements at optimal locations close to the sources is required [7,8]. In previous work, a reference microphone was located above the motor shaft to avoid physical interference with scanning microphones [6]. However, as motors are constructed to be increasingly smaller, the optimal position for a stationary reference microphone may not be accessible for actual measurement. In this research, strategies for small motor noise visualization without using a reference microphone have been explored. Due to the possibility of spatial interference between scanning and reference microphones as size of motors and distance between source and measurement surfaces were very small, it would be ideal to visualize very small noise sources with only scanning microphone measurements (eliminating reference microphone 
measurements). Only scanning microphones and current measurements for a motor were used to visualize sound sources. First, the current measurement of the motor was used as a reference signal for noise visualization, with scanning microphone measurements. However, the amplitude of the current measurement decreased very rapidly as frequency increased, so scanning microphone signals were combined with current measurements and used as moving reference signals. Motor noise visualization results based on different moving reference locations were estimated and presented in this study.

For major electro-magnetic force excitation frequencies, the consistency of motor noise visualization results from motor current and different moving reference locations were investigated. Also, improvements in motor noise visualization results were investigated for frequencies with relatively low current amplitude, using moving references located in various positions around the motor. Moreover, the possibility of motor noise reduction with an optimal capacitor connected to the motor power input by reducing the commutator arc was quantified. Additionally, the relationship between motor current and sound pressure at different locations for run-up operation of the motor at different rotational speeds was investigated.

In this study, noise sources for a small DC motor were investigated based on sound pressure measurement using scanning microphones and motor current. The measurement of motor current was used as a reference signal and combined with sound pressure measurements to estimate moving reference signals at various locations around the motor to improve sound visualization results. This method for sound visualization was determined to be appropriate for improving sound visualization for very small motors when reference microphones cannot be placed at optimal locations close to sources.

\section{Partial Fields and Transfer Functions between Sources and Sound Measurement}

For sound visualization of a source to be accurate, measurement of the sound field should be coherent. Otherwise, measurement pressure should be decomposed into coherent partial fields [7]. Partial field decomposition should also be used if the total measurement surface should be scanned with relatively few microphones and appropriate reference signals. The formulation for partial field decomposition starts by relating the source, reference, and field signals. Reference signals, $\mathbf{R}$, and field microphones signals, $\mathbf{Y}$, can be expressed using transfer functions to represent their relationship with source signals [7-9]:

$$
\begin{aligned}
& \mathbf{R}=\mathbf{G}_{\mathrm{rs}} \mathbf{S} \\
& \mathbf{Y}=\mathbf{G}_{\mathrm{ys}} \mathbf{S}
\end{aligned}
$$

where $\mathbf{s}$ represents source signals, and $\mathbf{G}_{\mathrm{rs}}$ and $\mathbf{G}_{\mathrm{ys}}$ are transfer functions between a source and reference, and a source and field signals, respectively. The cross-spectral matrix between reference signals and field microphone signals, $\mathbf{S}_{\mathrm{ry}}$, and the spectral matrices of the reference and field microphones signals, $\mathbf{S}_{\mathrm{rr}}$ and $\mathbf{S}_{\mathrm{yy}}$, can be written as

$$
\begin{aligned}
\mathbf{S}_{\mathrm{ry}} & =\mathrm{E}\left\{\mathbf{R} \mathbf{Y}^{\mathrm{H}}\right\}=\mathbf{G}_{\mathrm{rs}} \mathbf{S}_{\mathrm{ss}} \mathbf{G}_{\mathrm{ys}}{ }^{\mathrm{H}} \\
\mathbf{S}_{\mathrm{rr}} & =\mathrm{E}\left\{\mathbf{R} \mathbf{R}^{\mathrm{H}}\right\}=\mathbf{G}_{\mathrm{rs}} \mathbf{S}_{\mathrm{ss}} \mathbf{G}_{\mathrm{rs}}{ }^{\mathrm{H}} \\
\mathbf{S}_{\mathrm{yy}} & =\mathrm{E}\left\{\mathbf{Y} \mathbf{Y}^{\mathrm{H}}\right\}=\mathbf{G}_{\mathrm{ys}} \mathbf{S}_{\mathrm{ss}} \mathbf{G}_{\mathrm{ys}}{ }^{\mathrm{H}}
\end{aligned}
$$

The Hermitian of the cross-spectral matrix and the inverse of the reference spectral matrix are

$$
\begin{gathered}
\mathbf{S}_{\mathrm{ry}}{ }^{\mathrm{H}}=\mathbf{G}_{\mathrm{ys}} \mathbf{S}_{\mathrm{ss}} \mathbf{G}_{\mathrm{rs}}{ }^{\mathrm{H}} \\
\mathbf{S}_{\mathrm{rr}}{ }^{-1}=\left(\mathbf{G}_{\mathrm{rs}}{ }^{\mathrm{H}}\right)^{-1} \mathbf{S}_{\mathrm{ss}}{ }^{-1} \mathbf{G}_{\mathrm{rs}}{ }^{-1}
\end{gathered}
$$

In addition, $\mathbf{G}_{\mathrm{ys}}$ can be calculated by post-multiplying $\mathbf{S}_{\mathrm{ry}}{ }^{\mathrm{H}}$ by $\left(\mathrm{G}_{\mathrm{rs}}{ }^{\mathrm{H}}\right)^{-1} \mathbf{S}_{\mathrm{ss}}{ }^{-1}$, i.e.,

$$
\mathbf{G}_{\mathrm{ys}}=\mathbf{S}_{\mathrm{ry}}{ }^{\mathrm{H}}\left(\mathbf{G}_{\mathrm{rs}}{ }^{\mathrm{H}}\right)^{-1} \mathbf{S}_{\mathrm{ss}}{ }^{-1}
$$


and the transfer function between the reference and field microphones, $\mathbf{H}_{\mathrm{yr}}$, is then

$$
\mathbf{H}_{\mathrm{yr}}=\mathbf{Y} \mathbf{R}^{-1}=\mathbf{G}_{\mathrm{ys}} \mathbf{G}_{\mathrm{rs}}{ }^{-1}=\mathbf{S}_{\mathrm{ry}}{ }^{\mathrm{H}}\left(\mathbf{G}_{\mathrm{rs}}{ }^{\mathrm{H}}\right)^{-1} \mathbf{S}_{\mathrm{ss}}{ }^{-1} \mathbf{G}_{\mathrm{rs}}{ }^{-1}=\mathbf{S}_{\mathrm{ry}}{ }^{\mathrm{H}} \mathbf{S}_{\mathrm{rr}}{ }^{-1}
$$

Thus, the transfer function, $\mathbf{H}_{\mathrm{yr}}$, depends on the source and reference geometry. It is independent of source level. The autospectral matrix of the field microphones, $\mathbf{S}_{\mathrm{yy}}$, is then

$$
\mathbf{S}_{\mathrm{yy}}=\mathbf{G}_{\mathrm{ys}} \mathbf{S}_{\mathrm{ss}} \mathbf{G}_{\mathrm{ys}}{ }^{\mathrm{H}}=\mathbf{H}_{\mathrm{yr}} \mathbf{G}_{\mathrm{rs}} \mathbf{S}_{\mathrm{ss}} \mathbf{G}_{\mathrm{ys}}{ }^{\mathrm{H}}=\mathbf{H}_{\mathrm{yr}} \mathbf{S}_{\mathrm{ry}}=\mathbf{S}_{\mathrm{ry}}{ }^{\mathrm{H}} \mathbf{S}_{\mathrm{rr}}{ }^{-1} \mathbf{S}_{\mathrm{ry}}=\mathbf{P} \mathbf{P}^{\mathrm{H}}
$$

Hence, the partial field matrix, $\mathbf{P}$, is

$$
\mathbf{P}=\mathbf{S}_{\mathrm{ry}}{ }^{\mathrm{H}} \mathbf{S}_{\mathrm{rr}}{ }^{-1 / 2}=\mathbf{H}_{\mathrm{yr}} \mathbf{S}_{\mathrm{rr}}{ }^{1 / 2}=\mathbf{G}_{\mathrm{ys}} \mathbf{S}_{\mathrm{ss}}{ }^{1 / 2}
$$

The partial field matrix is considered to represent measurement pressure for noise source visualization in this research. The moving reference signal, $\mathbf{R}_{\mathrm{m}}$, is defined such that

$$
\mathbf{R}_{\mathrm{m}}=\mathrm{G}_{\mathrm{rms}} \mathbf{S}
$$

where $\mathbf{G}_{\mathrm{rms}}$ is the transfer function between the source and a moving reference. The moving reference is located closer to the source than a typical reference location. The transfer function, $\mathbf{H}_{\mathrm{yr}}$, can now be represented in terms of the moving reference as

$$
\mathbf{H}_{\mathrm{yr}}=\mathbf{Y} \mathbf{R}^{-1}=\mathbf{Y} \mathbf{R}_{\mathrm{m}}{ }^{-1} \mathbf{R}_{\mathrm{m}} \mathbf{R}^{-1}=\mathbf{G}_{\mathrm{ys}} \mathbf{G}_{\mathrm{rms}}{ }^{-1} \mathbf{G}_{\mathrm{rms}} \mathbf{G}_{\mathrm{rs}}{ }^{-1}=\mathbf{H}_{\mathrm{yrm}} \mathbf{H}_{\mathrm{rmr}}
$$

where $\mathbf{H}_{\mathrm{yrm}}$ is the transfer function between a moving reference and field microphones. Similarly, $\mathbf{H}_{\text {rmr }}$ is the transfer function between a stationary reference and moving reference. The partial field matrix, $\mathbf{P}$, based on a moving reference is

$$
\mathbf{P}=\mathbf{H}_{\mathrm{yr}} \mathbf{S}_{\mathrm{rr}}{ }^{1 / 2}=\mathbf{H}_{\mathrm{yrm}} \mathbf{H}_{\mathrm{rmr}} \mathbf{S}_{\mathrm{rr}}{ }^{1 / 2}=\mathbf{S}_{\mathrm{rmy}}{ }^{\mathrm{H}} \mathbf{S}_{\mathrm{rmrm}}{ }^{-1} \mathbf{S}_{\mathrm{rrm}}{ }^{\mathrm{H}} \mathbf{S}_{\mathrm{rr}}{ }^{-1} \mathbf{S}_{\mathrm{rr}}{ }^{1 / 2}=\mathbf{S}_{\mathrm{rmy}}{ }^{\mathrm{H}} \mathbf{S}_{\mathrm{rmrm}}{ }^{-1} \mathbf{S}_{\mathrm{rrm}}{ }^{\mathrm{H}} \mathbf{S}_{\mathrm{rr}}{ }^{-1 / 2}=\mathbf{G}_{\mathrm{ys}} \mathbf{S}_{\mathrm{ss}}{ }^{1 / 2}
$$

In this context, sound pressure measurement taken via scanning microphones was used as the moving reference signal and motor current measurement was used as the fixed reference.

\section{Sound Visualization}

An acoustical holography procedure [10], which also could be described as an inverse system procedure, was implemented to visualize motor noise with current measurement as a reference. Acoustical holography was first introduced for projecting measurements with spherical coordinates, followed by a version with cylindrical coordinates [11,12]. An alternative holography procedure, statistically optimized near-field acoustical holography (SONAH), was derived to reduce spatial truncation and the size of the measurement surface $[13,14]$. SONAH was also modified for the projection of measurements with cylindrical coordinates [15]. Cylindrical SONAH was implemented to visualize noise radiated from power seat slide motors and small DC motors [16]. By using fixed reference signals during measurement, a scan could be completed with a relatively small number of microphones for successful acoustical holography reconstruction $[7,17]$. In this study, cylindrical SONAH was implemented to identify noise sources in a small DC motor with motor current used as a reference signal and sound pressure measurements used as both scanning and moving reference signals. A more detailed derivation of cylindrical SONAH has been provided in a previous work $[6,15]$, so SONAH is described relatively briefly here.

Cylindrical SONAH is based on the assumption that sound pressure $p(\mathbf{r})$ at an arbitrary position can be represented as a linear combination of measured sound pressure data, $p\left(\mathbf{r}_{h, j}\right)$ [15]:

$$
p(\mathbf{r}) \approx \sum_{j=1}^{J} c_{j}(\mathbf{r}) \cdot p\left(\mathbf{r}_{h, j}\right)
$$


Sound pressure on a cylindrical surface of radius $r$ can be expressed as

$$
p(r, \phi, z)=\sum_{m=-\infty}^{m=\infty} \frac{1}{2 \pi} \int_{-\infty}^{\infty} P_{m}\left(r, k_{z}\right) e^{i m \phi} e^{i k_{z} z} d k_{z}
$$

where $P_{m}\left(r, k_{z}\right)$ is the cylindrical wave number spectrum of $p_{m}(r, \phi, z)$ for the $m$ th circumferential component of the sound field, and $k_{z}$ is the axial component of the wave number. The wave number spectrum at radius $r$ can also be expressed in terms of the wave number spectrum of the sound field on a cylindrical source surface of radius $r_{s}$ :

$$
P_{m}\left(r, k_{z}\right)=\frac{H_{m}^{(1)}\left(k_{r} r\right)}{H_{m}^{(1)}\left(k_{r} r_{s}\right)} P_{m}\left(r_{s}, k_{z}\right)
$$

where $H_{m}^{(1)}$ is the $m$ th order Hankel function and the radial wave number is

$$
k_{r}=\left[\begin{array}{ccc}
\sqrt{k^{2}-k_{z}^{2}} & \text { for } & |k| \geq\left|k_{z}\right| \\
i \sqrt{k_{z}^{2}-k^{2}} & \text { for } & |k|<\left|k_{z}\right|
\end{array}\right.
$$

The three-dimensional cylindrical wave function, $\Phi_{k_{z}, m}(r, \phi, z)$, was defined as

$$
\Phi_{k_{z}, m}(\mathbf{r})=\Phi_{k_{z}, m}(r, \phi, z) \equiv \frac{H_{m}^{(1)}\left(k_{r} r\right)}{H_{m}^{(1)}\left(k_{r} r_{s}\right)} e^{i m \phi} e^{i k_{z} z}, \quad r \geq r_{s}
$$

The same coefficients $c_{j}$ in Equation (15) also provide a good estimation for the cylindrical wave functions:

$$
\Phi_{k_{z q}, m}(\mathbf{r}) \approx \sum_{j=1}^{J} c_{j}(\mathbf{r}) \Phi_{k_{z q}, m}\left(\mathbf{r}_{h, j}\right), m=1 \ldots M, q=1 \ldots N
$$

Coefficients $c_{j}$ can be estimated from the cylindrical wave functions at measurement and reconstruction locations by using statistically optimal or least square solutions. Radial particle velocity on the reconstruction surface, $u_{r}(\mathbf{r})$, can be found using Euler's equation:

$$
u_{r}(\mathbf{r})=\frac{1}{i \rho_{o} \omega} \frac{\partial p(\mathbf{r})}{\partial r}
$$

Radial particle velocity, $u_{r}(\mathbf{r})$, is estimated from the spatial distribution of sound pressure as

$$
u_{r}(\mathbf{r}) \approx \mathbf{p}^{\mathrm{T}}\left(\mathbf{r}_{h}\right) \mathbf{d}(\mathbf{r})
$$

where $\mathbf{d}(\mathbf{r})$ is the transfer matrix between measurement pressure and reconstructed particle velocity.

Pressure and particle velocity can be reconstructed at other surfaces, such as source surfaces, from measurement pressure. More detailed and accurate information about the source can be obtained using reconstructed properties than with measurement pressure alone.

\section{Measurement Description}

Sound pressure and current for a motor rotating at constant speed were measured on a cylindrical surface to enable reconstruction of the particle velocity of a source surface. The measurement of sound pressure was achieved in a way similar to in previous work, where it is described in detail [6]. The same motor and scanning microphones were used for measurement, but reference signals were taken from motor current. For measurements taken in previous studies, reference signals were taken from a reference microphone located above the motor [6]. However, there was no reference microphone used in this work, and motor current was measured to provide reference signals instead. This approach for 
taking measurements without a reference microphone is useful for visualization of noise radiated from very small motors and other micro structures. For example, if the size of the motor is smaller than that of a microphone, there will be no space for a reference microphone to be placed. Furthermore, one critical reason for using the same motor as in previous research was so sound visualization results could be compared and confirmed more conveniently when using different reference signals for the same motor. Overall schematic of the system for measurement and sound source visualization is shown in Figure 1a. The motor and microphones used for noise measurement are shown in Figure 1b. Microphones 1 to 4 were located sequentially from the bottom to top of the motor, as shown in Figure $1 \mathrm{~b}$, which represents zero degrees and has each scan rotated 15 degrees counter-clockwise (CCW). The number of measurements taken to cover the complete circumference was twenty four. The spacing between the microphones was $2 \mathrm{~cm}$, and the distance from each microphone to the surface of the motor was $1 \mathrm{~cm}$. The resistor and capacitor connected between the power supply and motor input are shown in Figure 1c. The voltage of the resistor shown in Figure 1c was measured to estimate the motor current. Also, a diagram showing how the motor power supply was connected to a resistor for measuring the current provided to the motor is shown in Figure 2.

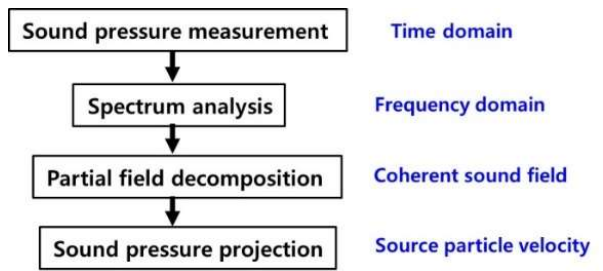

(a)

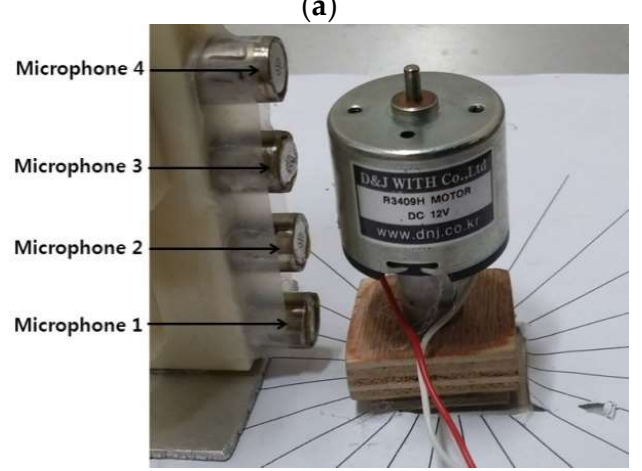

(b)

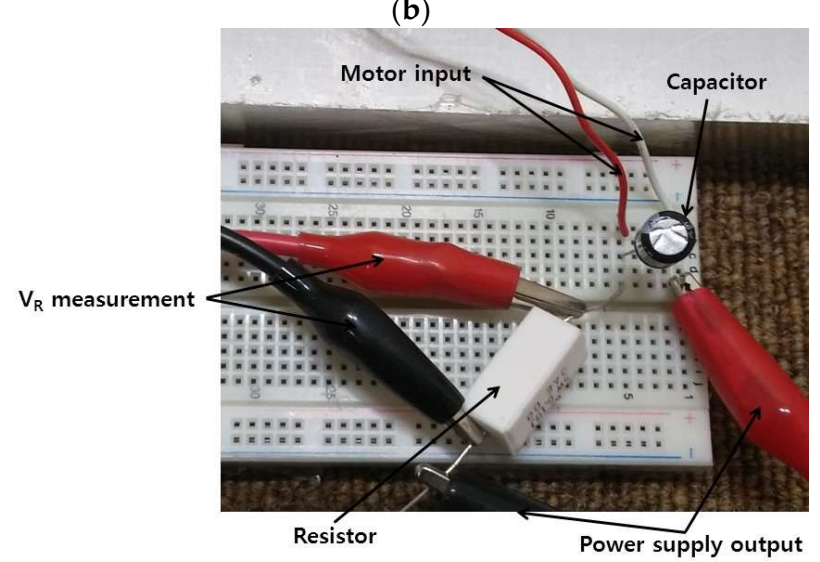

(c)

Figure 1. Overall motor noise measurement and visualization: (a) measurement and visualization procedure (b) motor and microphones; (c) capacitor and resistor. 


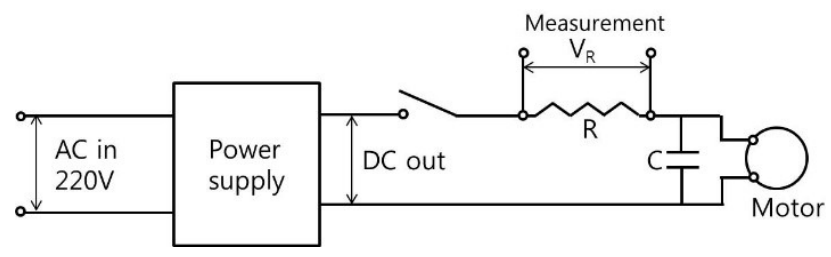

Figure 2. Motor power supply and resistor for measurement of current provided to the motor.

In addition to scanning the entire surface of the motor housing for noise visualization, sound pressure was also measured in a run-up test with microphones located at zero degrees. Power supply from $6 \mathrm{~V}$ to $15 \mathrm{~V}$ in increments of $0.3 \mathrm{~V}$ was provided to the motor for the run-up tests. Similarly, sound pressure was measured with various capacitors at the zero-degree microphone location.

A total of four scanning microphones were used for the measurements taken in this study. Electret condenser microphones powered with a $9 \mathrm{~V}$ battery were used as scanning microphones and more details of the microphones were described in previous work [17]. The microphones were calibrated at $1000 \mathrm{~Hz}, 94 \mathrm{~dB}$, and connected to a microphone amplifier. Output from the microphone amplifier and voltage measurements from the resistor to measure motor current were directed to an analog digital converter which was connected to a laptop computer, and the measurement data was saved on the laptop. All signals were sampled at $44.1 \mathrm{kHz}$. The Hann window was applied to all microphone and current measurements, except for the results shown in the time domain. For discrete Fourier transform, frame size of 11,025 points, overlap of $50 \%$, and frequency resolution of $4 \mathrm{~Hz}$ was applied for all results.

\section{Measurement Results}

Motor noise and current were measured under motor run-up conditions with different rotational speeds by varying the motor input voltage, which was useful for characterizing the noise directly related to rotational forces and structural or acoustical resonances. Also, motor noise and current were measured under a constant motor rotational speed of $4960 \mathrm{rpm}$ at $12 \mathrm{~V}$, with various different capacitors as shown in Figures 1 and 2 to reduce motor noise related to brush and commutator arcs by installing various capacitances in the motor power input. Finally, sound pressure and current for a motor rotating at constant speed were measured on a cylindrical surface, scanning the entire surface of the motor to reconstruct the particle velocity of source surfaces. Measurements were taken for a motor rotating both counter-clockwise (CCW) and clockwise (CW) at a constant speed of $4960 \mathrm{rpm}$ and $5080 \mathrm{rpm}$, respectively. There was slight deviation in motor rotational speed when the motor was rotating in different directions, but the nominal power supply output voltage remained the same, $12 \mathrm{~V}$. The values for resistance and capacitance for measuring current and reducing arcs in the motor, as shown in Figures 1 and 2, were $0.1 \Omega$ and $100 \mu \mathrm{F}$ for all measurements presented in this research unless described otherwise.

Motor current measurements in the time domain with various motor rotational speeds were taken by adjusting power supply voltage as shown in Figure 3. There were two brushes and three commutators poles, such that every sixth waveform corresponded to the same brush and commutator pole; every third waveform corresponded to the same commutator pole; and every second waveform corresponded to the same brush. Even for the low motor speed of $2480 \mathrm{rpm}$, the current measurement waveform deviated significantly from the harmonic waveform. One major reason for this deviation could be the relatively small size of the commutator, which was $6.25 \mathrm{~mm}$ in diameter, and a lack of precision manufacturing. For even smaller commutators, as in smaller motors, the waveform for motor current would be likely to deviate even more from the harmonic waveform. 


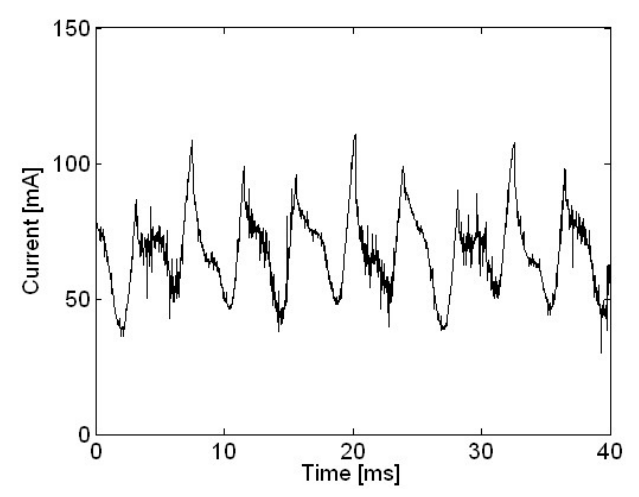

(a)

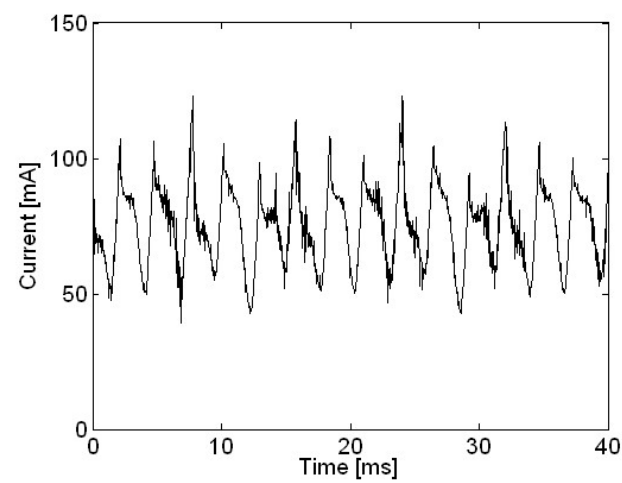

(c)

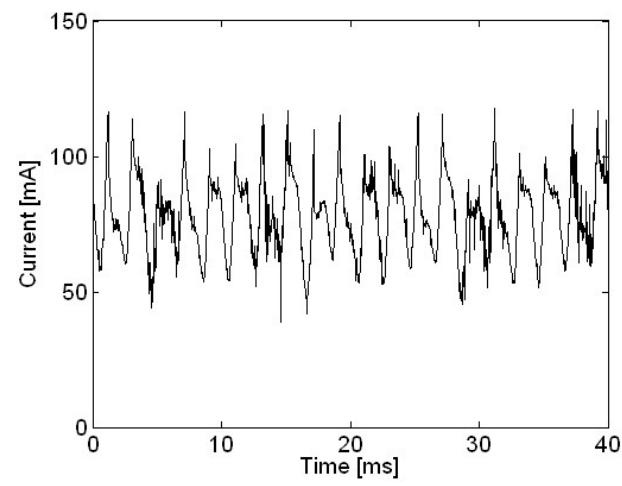

(e)

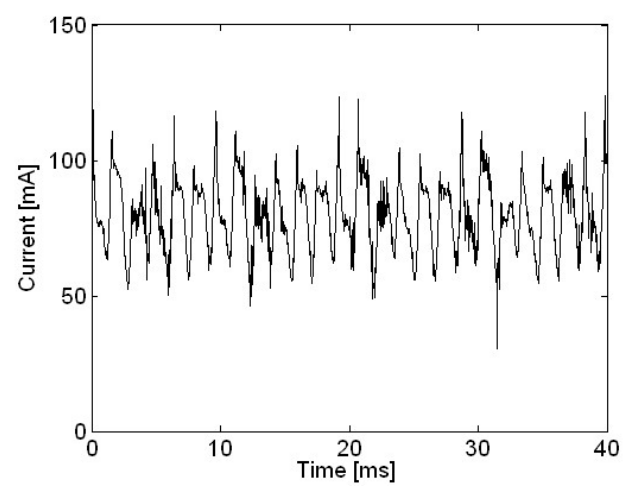

(g)

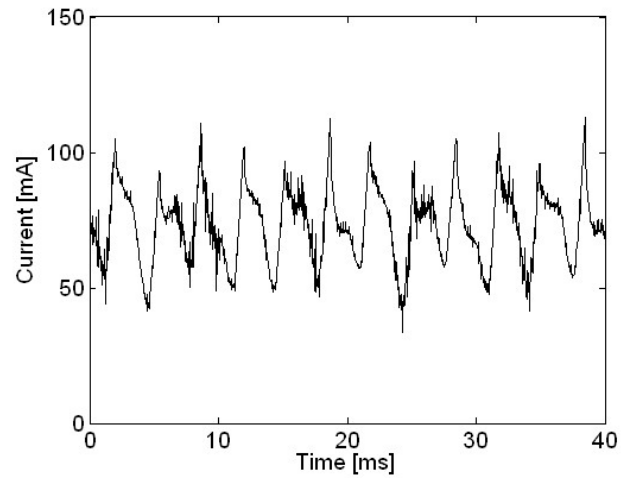

(b)

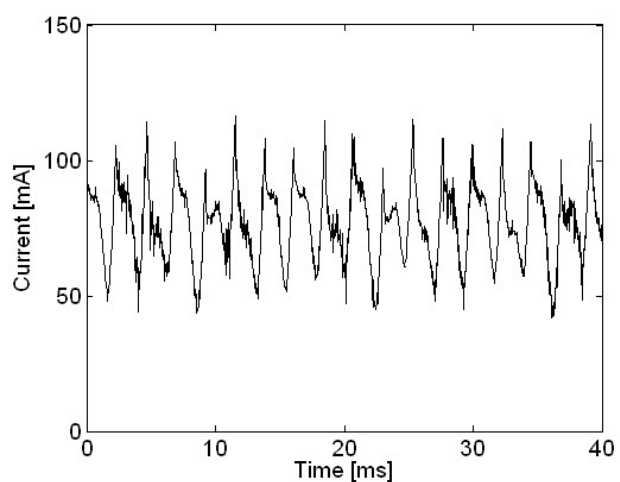

(d)

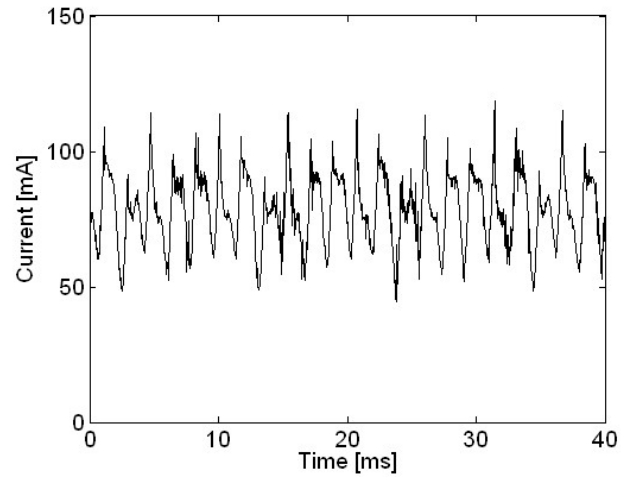

(f)

Figure 3. Motor current measurement in the time domain with various motor rotational speeds: (a) $2480 \mathrm{rpm}$; (b) $3100 \mathrm{rpm}$; (c) $3720 \mathrm{rpm}$; (d) $4340 \mathrm{rpm}$; (e) $4960 \mathrm{rpm}$; (f) $5580 \mathrm{rpm}$; (g) $6200 \mathrm{rpm}$. 
Motor current measurements with different motor rotational speed are shown in Figure 4. Only frequencies corresponding to a multiple of rotational speed or fundamental frequencies are included since they represent points of interest with relatively higher input power. At low frequencies, the current level at major peaks was almost identical regardless of motor speed. In contrast, as motor speed rose, current level increase at high frequencies was dominant. Motor current was represented in $\mathrm{dB}$ using a reference value of $20 \mu \mathrm{A}$. Distortion of the current waveform at higher frequencies was clearly shown at higher motor speeds. Motor current with various motor rotational speeds is shown in Figure 5. The range of motor speeds was between 2480 and $6200 \mathrm{rpm}$, which corresponded to a power supply voltage of $6 \mathrm{~V}$ and $15 \mathrm{~V}$. Very clear motor current level was shown below $600 \mathrm{~Hz}$, or sixth order of motor rotational speed. Motor current level decreased rapidly as frequency increased, and current level was significantly lower above $4 \mathrm{kHz}$.

Similarly, sound pressure at the center of the motor with various motor rotational speeds is shown in Figure 6. The sound pressure measurement location at the center of the motor corresponded to the position of microphone 3, as shown in Figure 1b. A relatively similar contour can be seen in current and sound pressure measurement results for frequencies below $1 \mathrm{kHz}$, as in Figures $5 \mathrm{a}$ and $6 \mathrm{a}$. In contrast, even though the current level was very low, the sound pressure measurement level was relatively high for frequencies above $7 \mathrm{kHz}$ as shown in Figures $5 \mathrm{~h}$ and $6 \mathrm{~h}$. Transfer functions between current and sound pressure measurement at the motor center were estimated and are shown in Figure 7. One of the highest peaks for the transfer functions at the fundamental frequencies of motor rotational speed, possibly related to unbalanced forces in the motor, is clearly shown in Figure 7a. Also, the peaks for the transfer functions at frequencies above $7 \mathrm{kHz}$, possibly related to resonance of the motor housing, are clearly shown in Figure 7h [6].

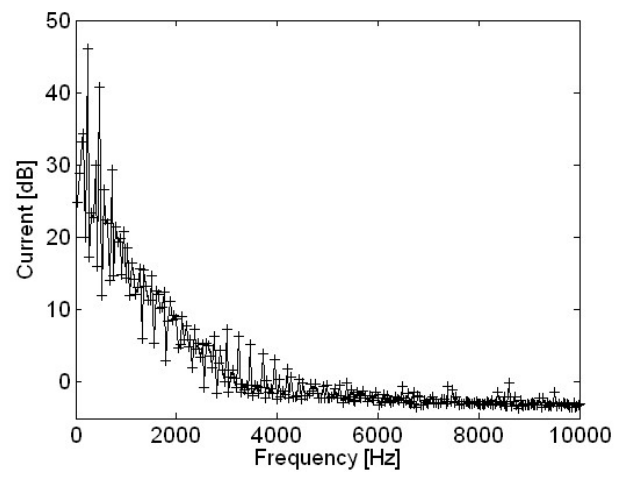

(a)

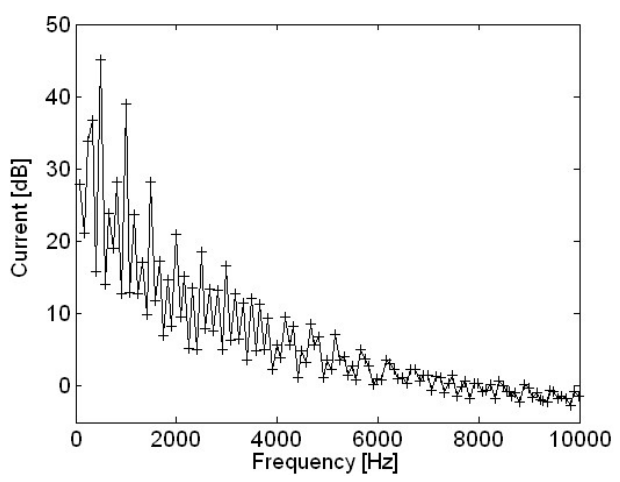

(c)

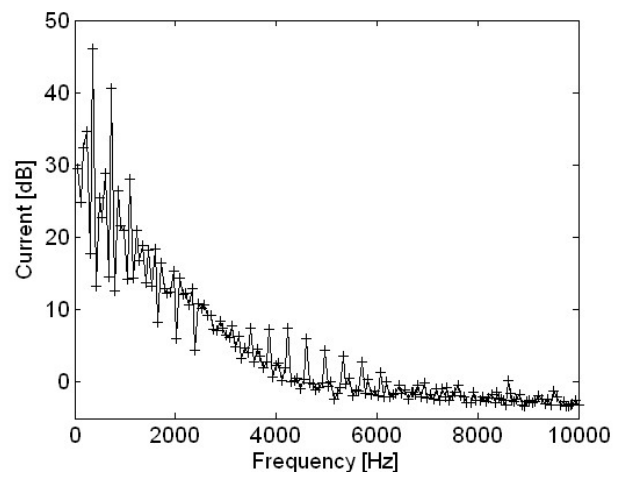

(b)

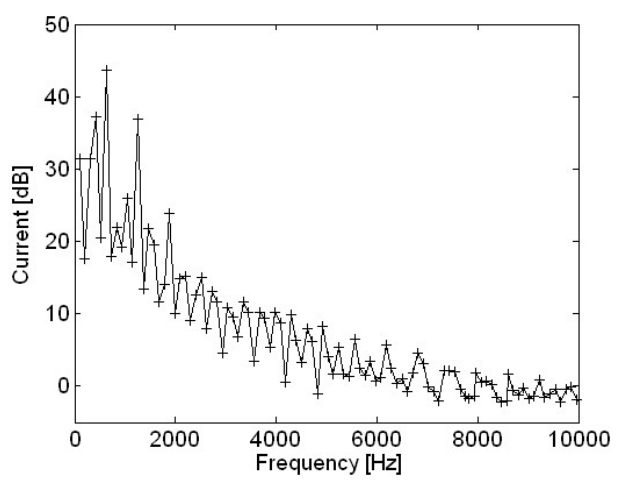

(d)

Figure 4. Motor current measurement with different motor rotational speeds: (a) $2480 \mathrm{rpm}$; (b) $3720 \mathrm{rpm}$; (c) $4960 \mathrm{rpm}$; (d) $6200 \mathrm{rpm}$. 


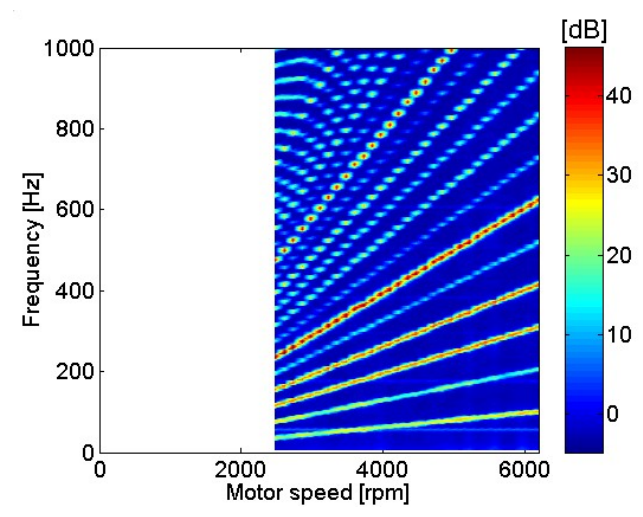

(a)

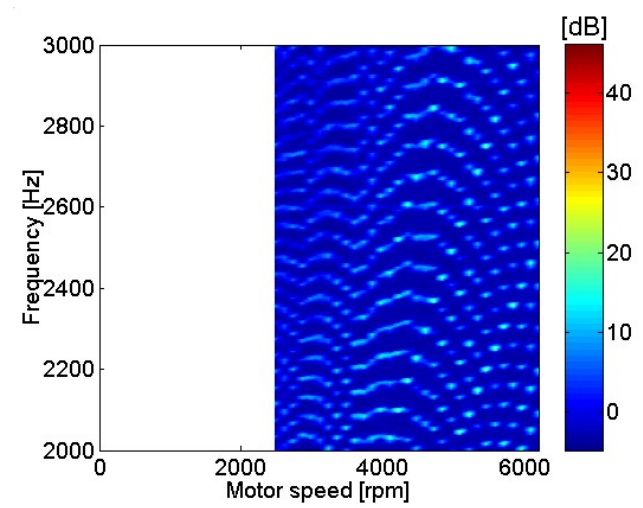

(c)

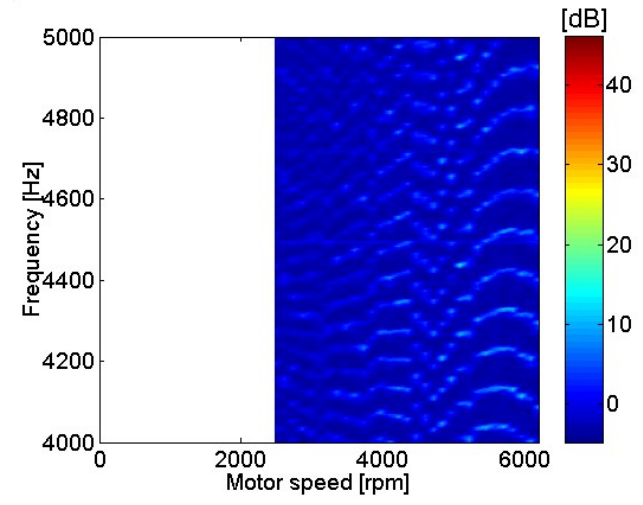

(e)

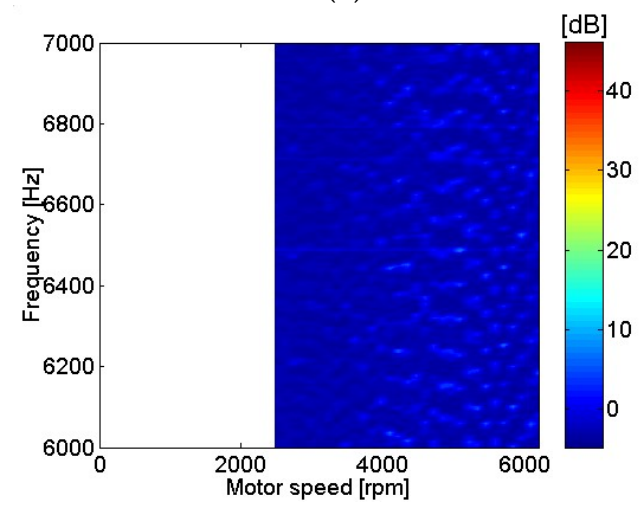

(g)

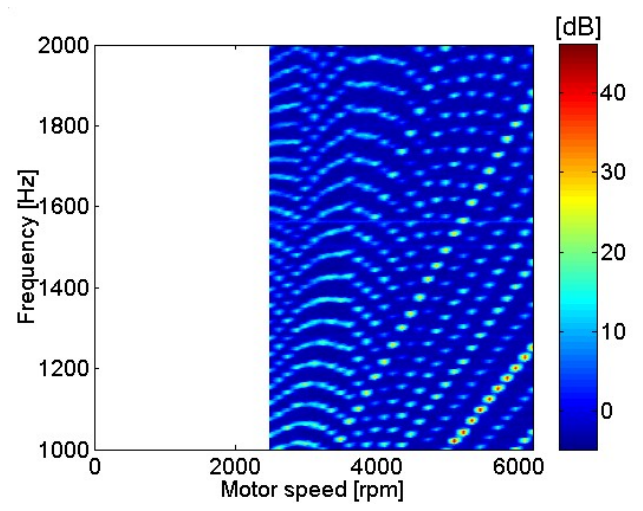

(b)

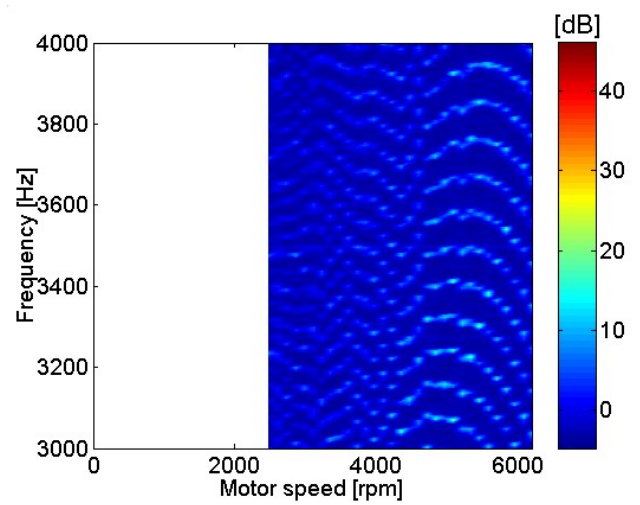

(d)

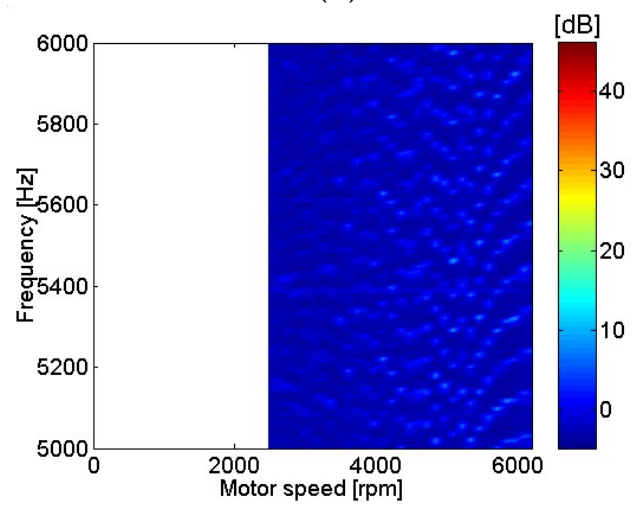

(f)

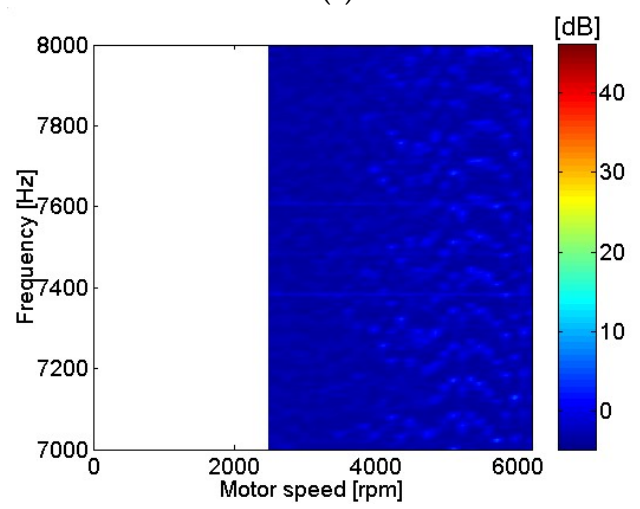

(h)

Figure 5. Motor current at various motor speeds: (a) $0-1 \mathrm{kHz}$; (b) $1-2 \mathrm{kHz}$; (c) $2-3 \mathrm{kHz}$; (d) $3-4 \mathrm{kHz}$; (e) 4-5 kHz; (f) $5-6 \mathrm{kHz}$; (g) 6-7 kHz; (h) $7-8 \mathrm{kHz}$. 


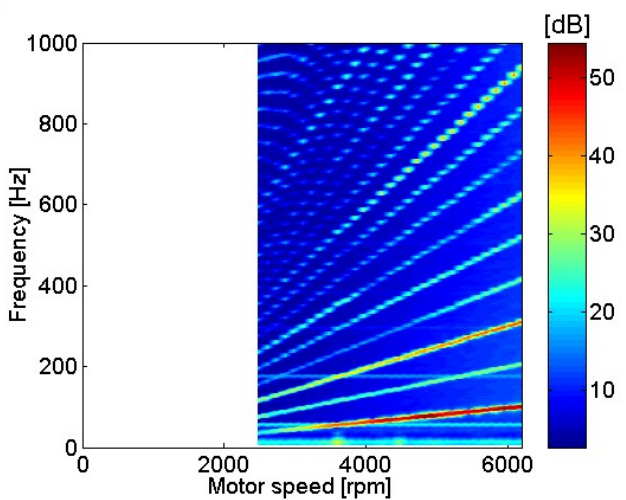

(a)

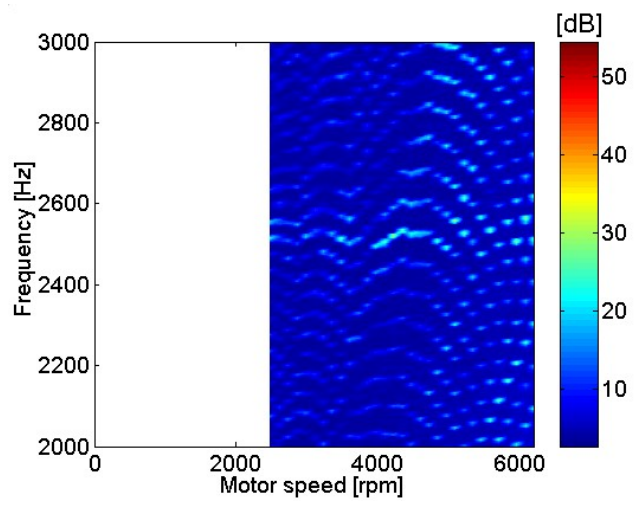

(c)

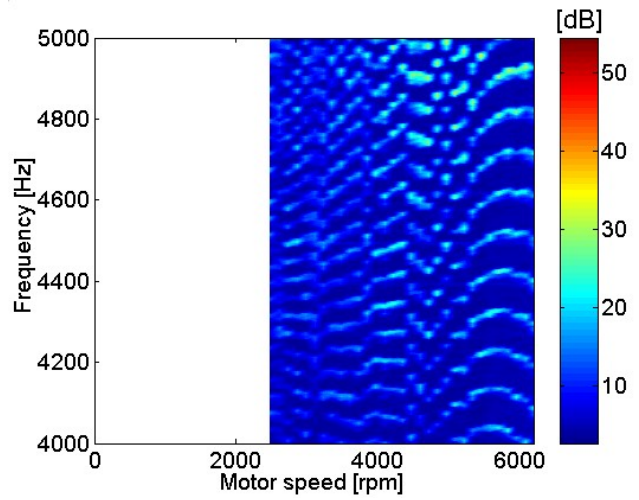

(e)

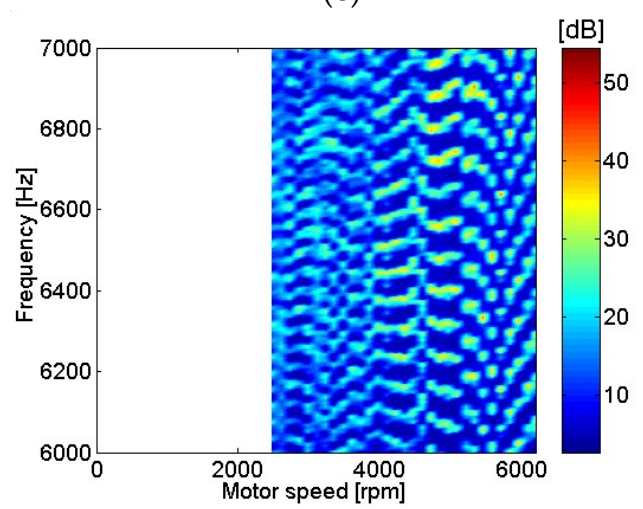

(g)

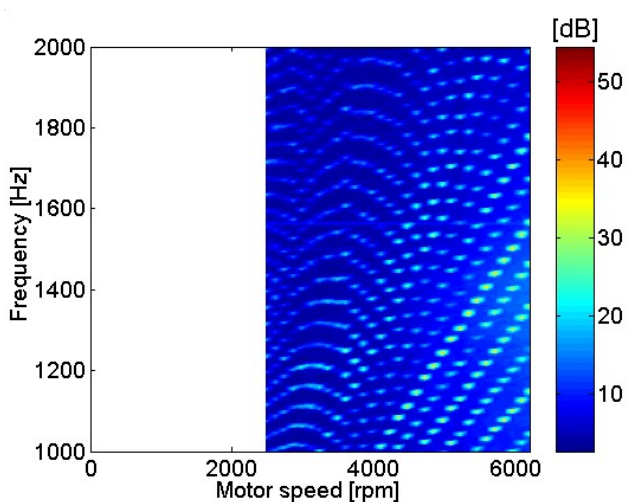

(b)

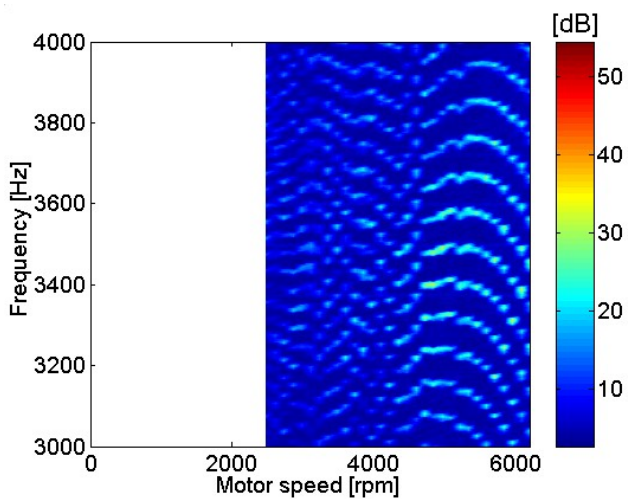

(d)

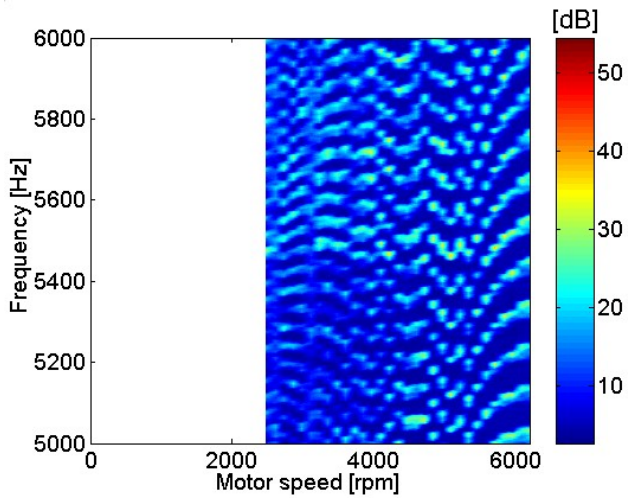

(f)

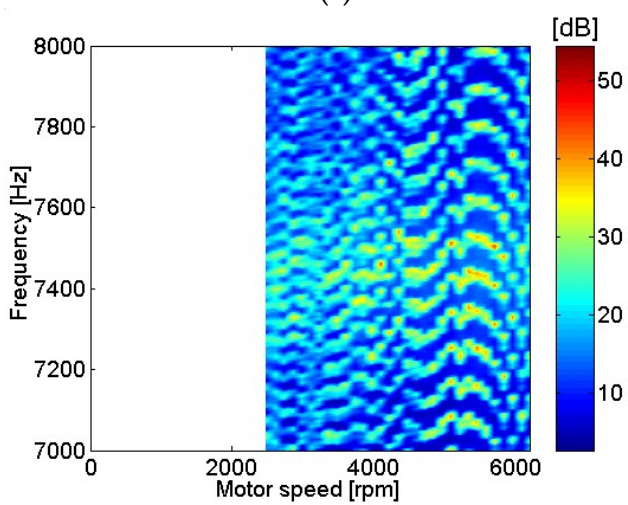

(h)

Figure 6. Sound pressure at various motor speeds: (a) $0-1 \mathrm{kHz}$; (b) $1-2 \mathrm{kHz}$; (c) $2-3 \mathrm{kHz}$; (d) $3-4 \mathrm{kHz}$; (e) 4-5 kHz; (f) $5-6 \mathrm{kHz}$; (g) 6-7 kHz; (h) $7-8 \mathrm{kHz}$. 


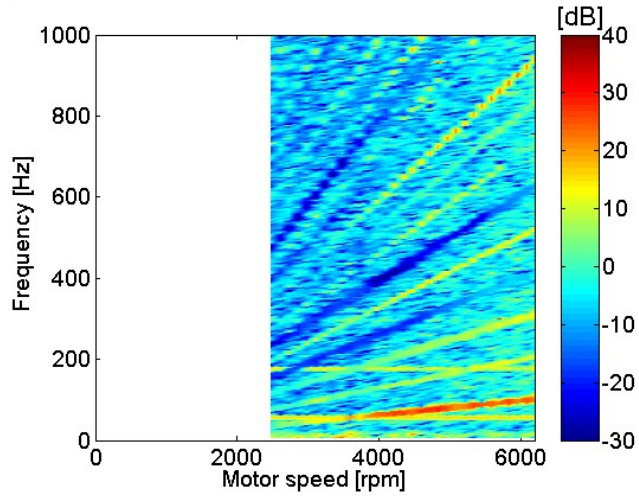

(a)

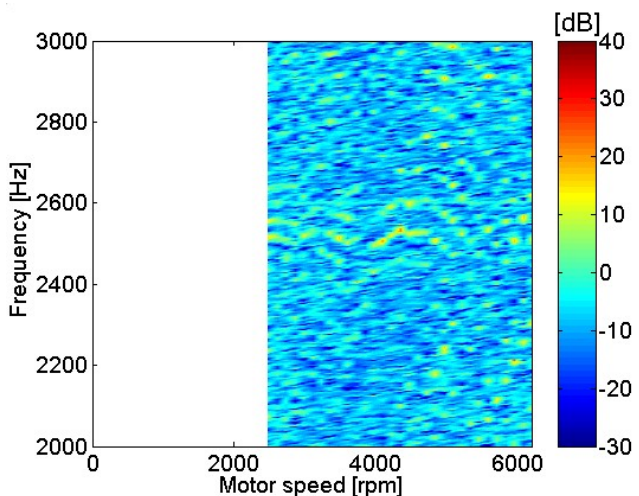

(c)

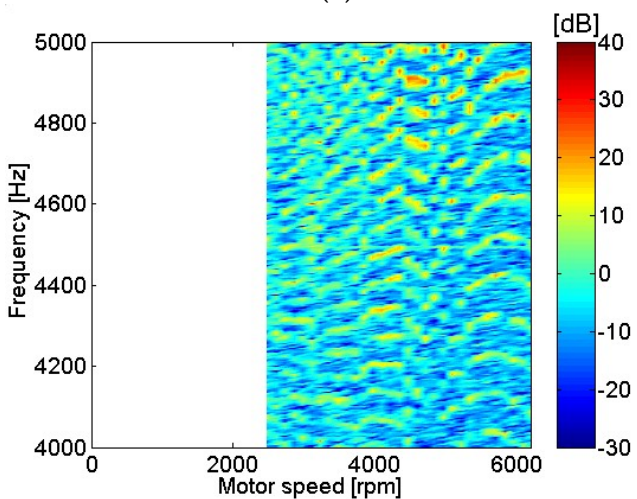

(e)

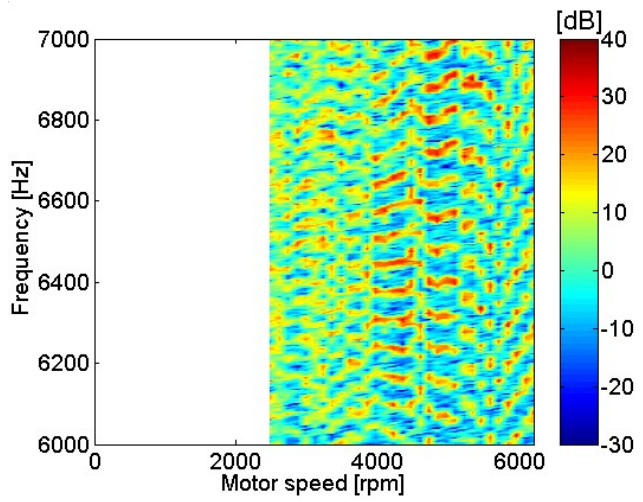

(g)

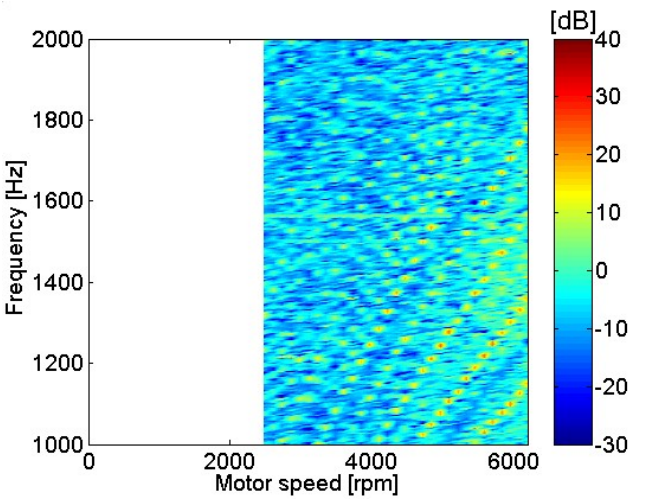

(b)

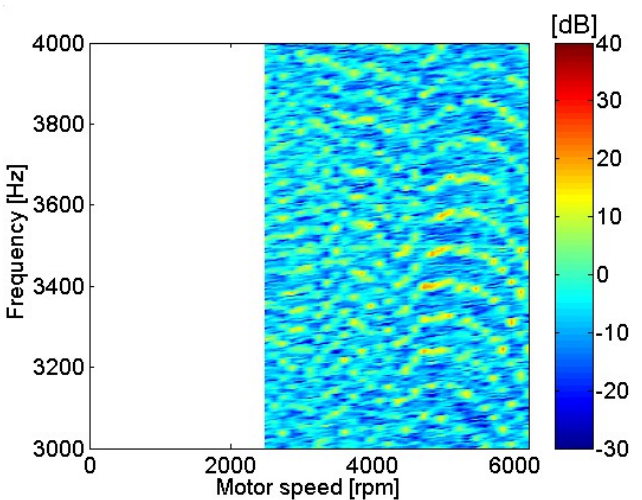

(d)

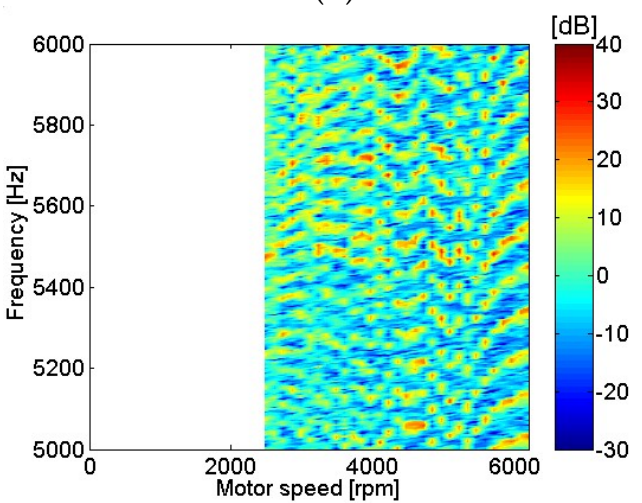

(f)

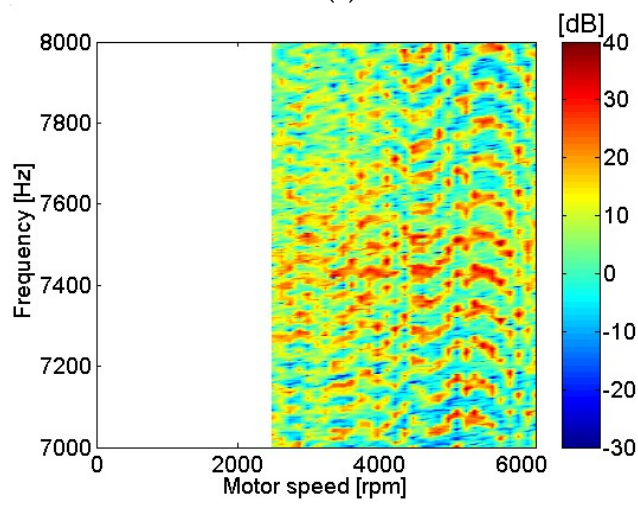

(h)

Figure 7. Transfer functions between sound pressure and motor current at various motor speeds: (a) 0-1 kHz; (b) 1-2 kHz; (c) 2-3 kHz; (d) 3-4 kHz; (e) 4-5 kHz; (f) 5-6 kHz; (g) 6-7 kHz; (h) 7-8 kHz. 
Sound pressure at the top of the motor at various motor rotational speeds is shown in Figure 8. The sound pressure measurement location at the top of the motor corresponded to the position of microphone 4, as shown in Figure 1b. The relatively similar contour between results is shown in sound pressure measurements from different locations around the motor center and top in the frequency range below $1 \mathrm{kHz}$, as shown in Figures 6a and 8a. The sound pressure measurement level was relatively high at frequencies around $7.2 \mathrm{kHz}$, as shown in Figure $8 \mathrm{~h}$. The transfer functions between current and sound pressure measurement at the top of the motor were estimated and are shown in Figure 9. The magnitude of the transfer function level was highest at frequencies around $7.2 \mathrm{kHz}$, as shown in Figure 9h. The amplitude ratio between sound pressure and current measurement at the top of the motor at various motor speeds is shown in Figure 10.

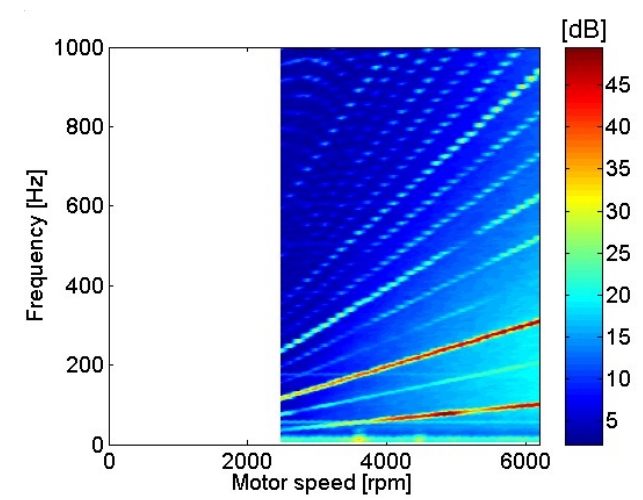

(a)

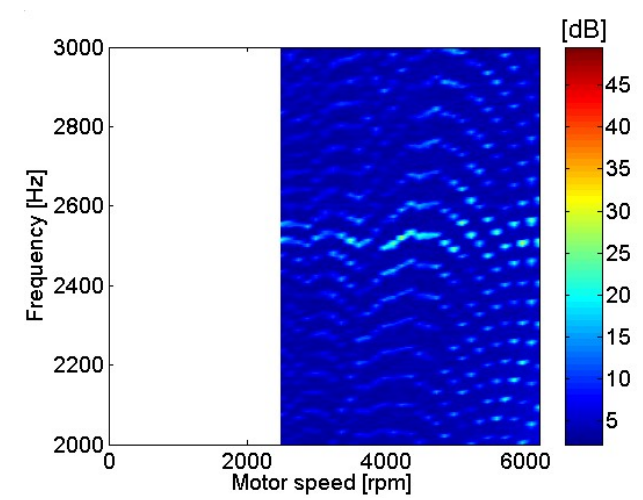

(c)

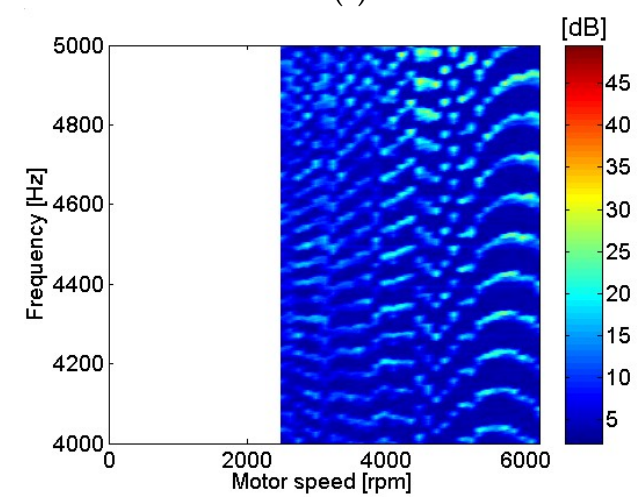

(e)

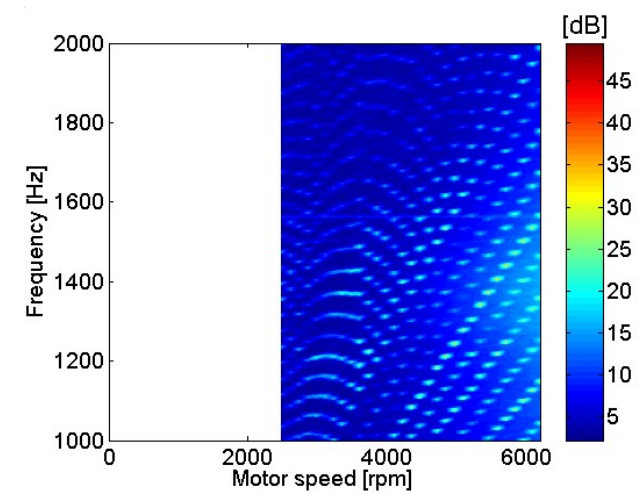

(b)

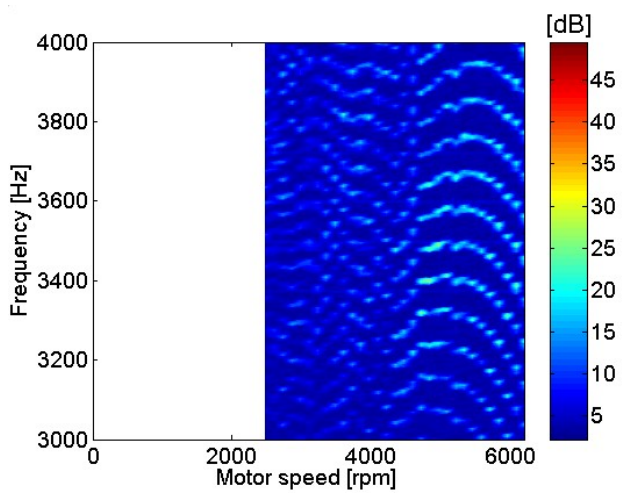

(d)

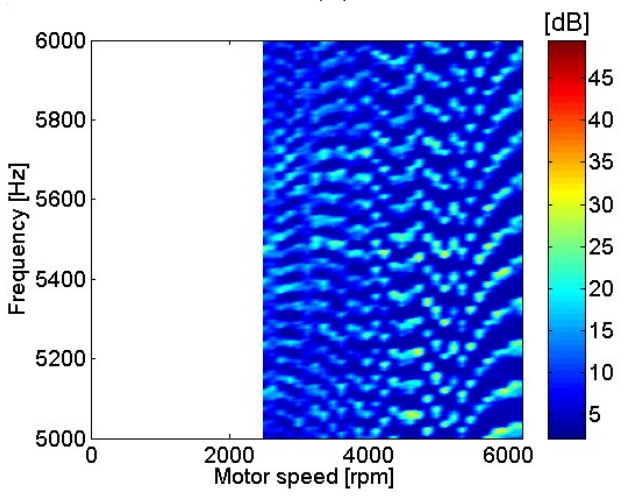

(f)

Figure 8. Cont. 


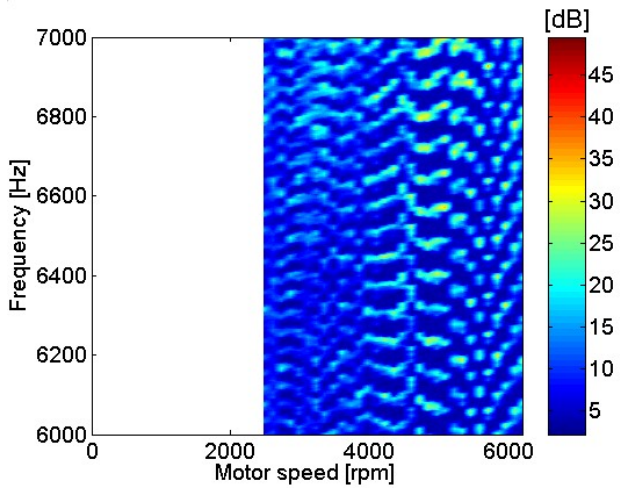

(g)

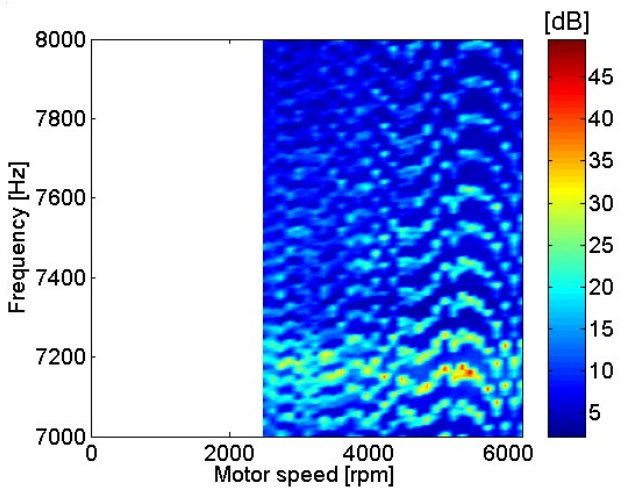

(h)

Figure 8. Sound pressure on top at various motor speeds: (a) $0-1 \mathrm{kHz}$; (b) $1-2 \mathrm{kHz}$; (c) $2-3 \mathrm{kHz}$; (d) 3-4 kHz; (e) 4-5 kHz; (f) 5-6 kHz; (g) 6-7 kHz; (h) 7-8 kHz.

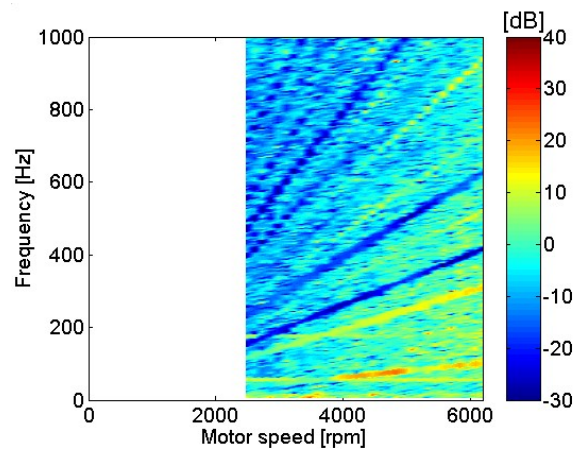

(a)

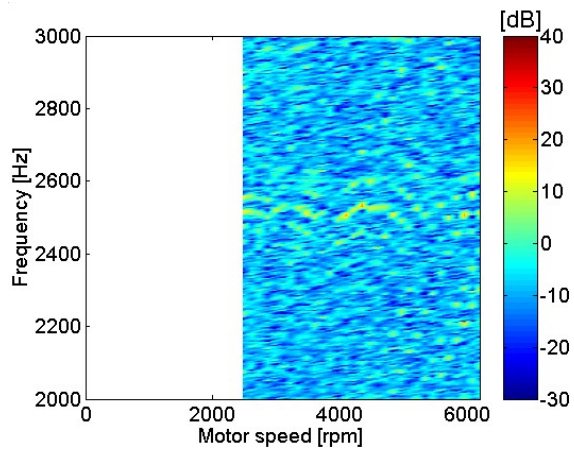

(c)

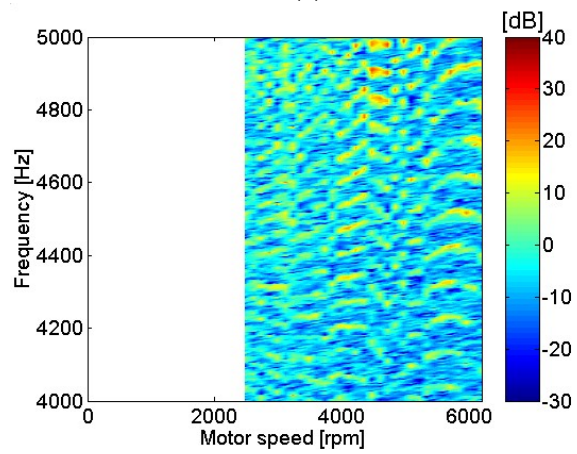

(e)

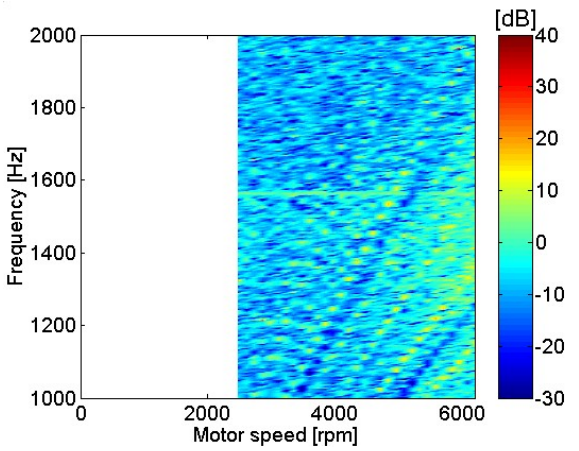

(b)

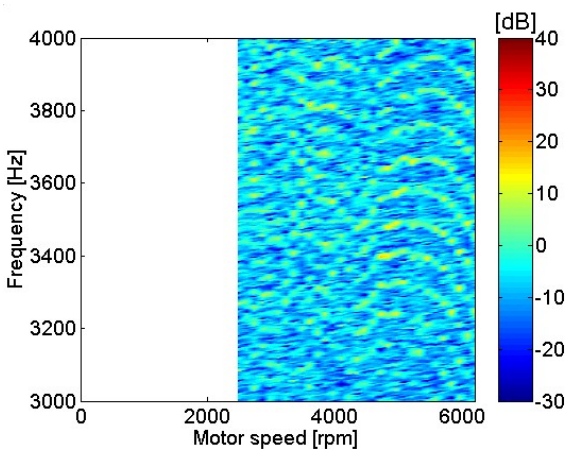

(d)

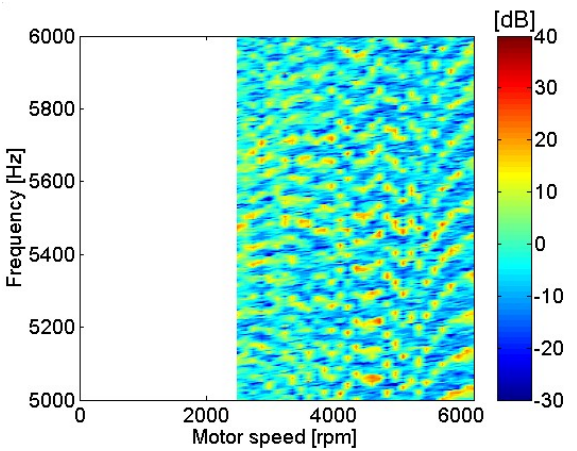

(f)

Figure 9. Cont. 


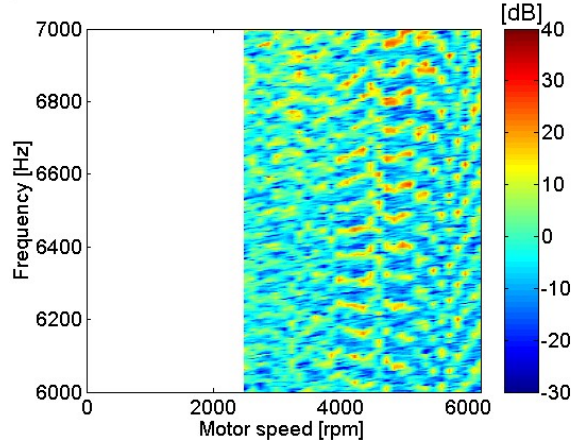

(g)

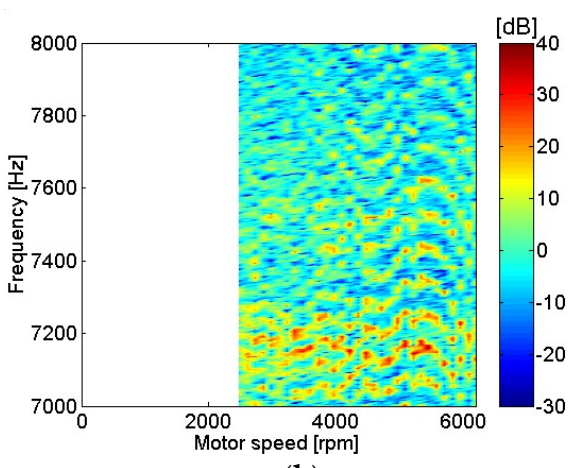

(h)

Figure 9. Transfer functions between sound pressure and motor current on top at various motor speeds: (a) 0-1 kHz; (b) 1-2 kHz; (c) 2-3 kHz; (d) 3-4 kHz; (e) $4-5 \mathrm{kHz}$; (f) $5-6 \mathrm{kHz}$; (g) 6-7 kHz; (h) 7-8 kHz.

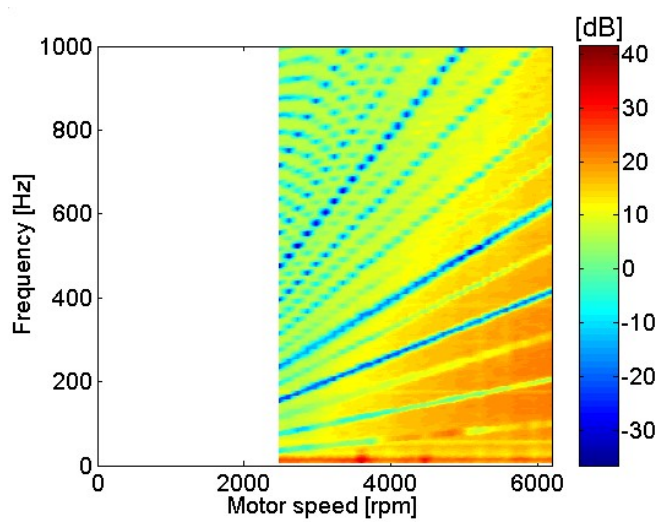

(a)

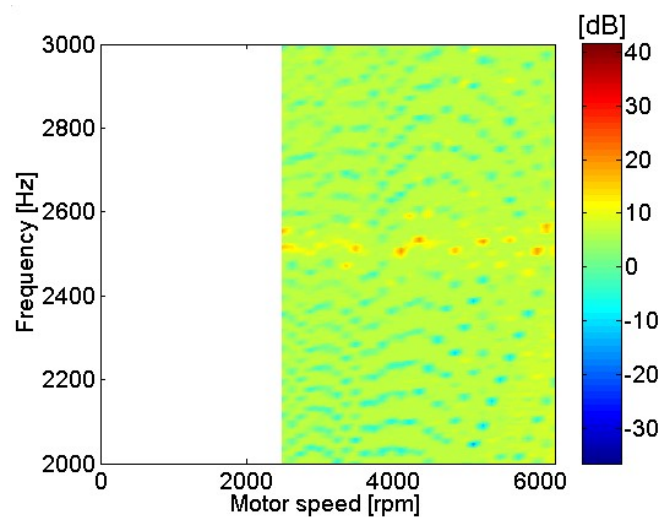

(c)

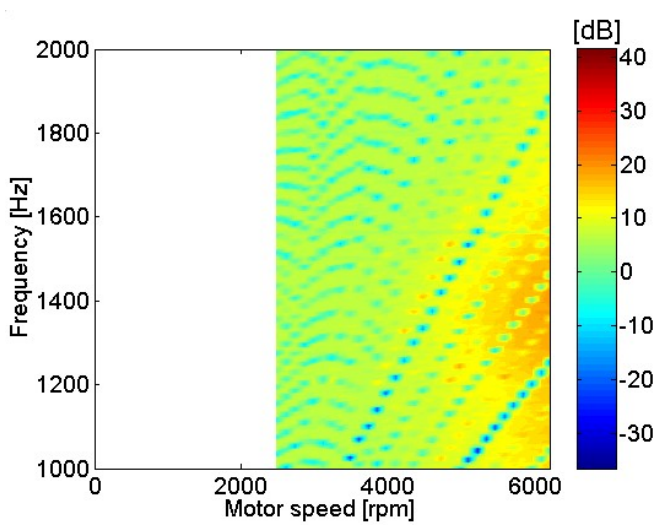

(b)

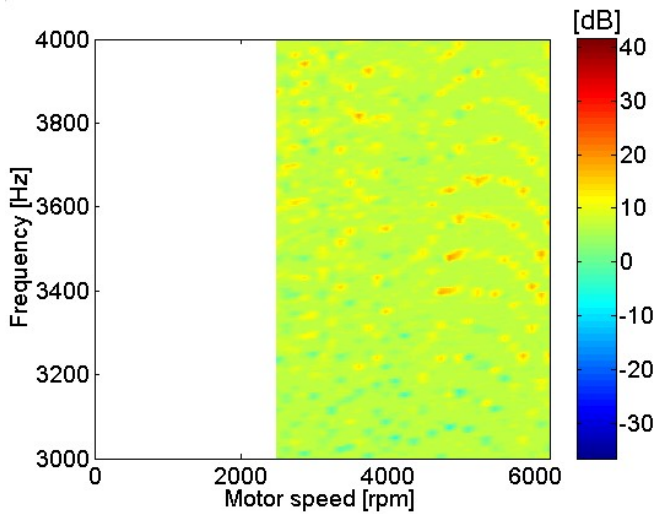

(d)

Figure 10. Cont. 


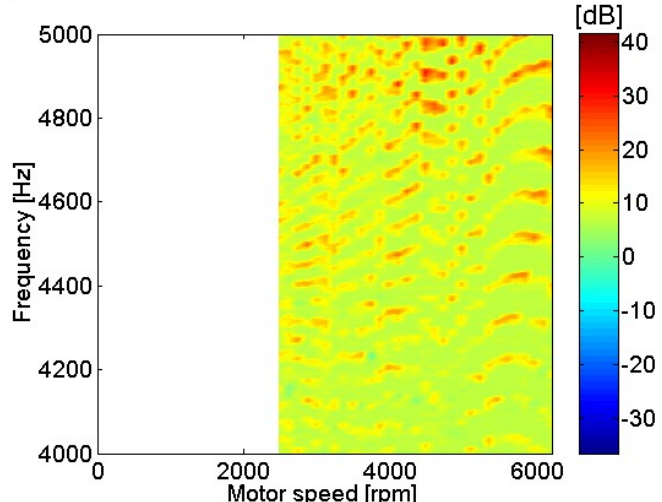

(e)

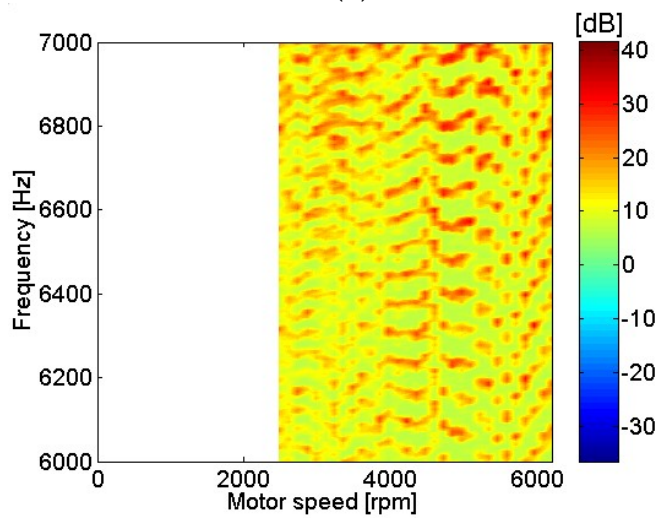

(g)

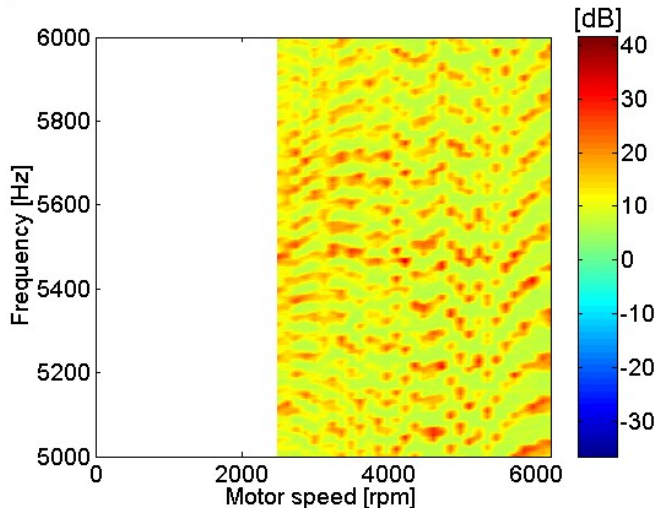

(f)

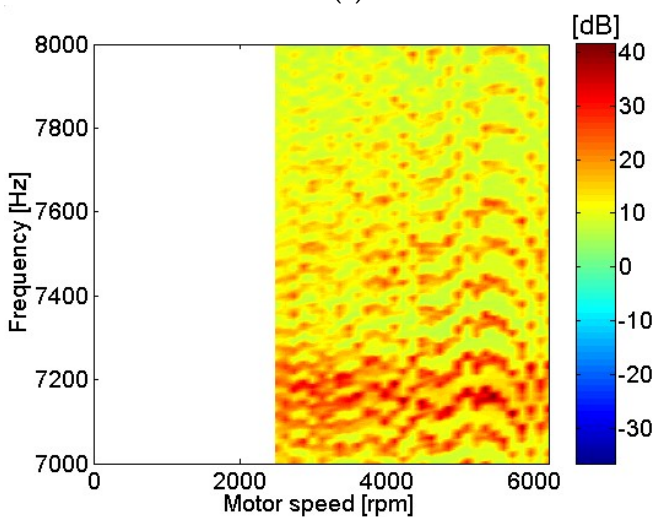

(h)

Figure 10. Amplitude ratio of sound pressure and motor current on top at various motor speeds: (a) 0-1 kHz; (b) 1-2 kHz; (c) 2-3 kHz; (d) 3-4 kHz; (e) 4-5 kHz; (f) 5-6 kHz; (g) 6-7 kHz; (h) 7-8 kHz.

Motor current measurements with various capacitances in the time domain are shown in Figure 11. The resistance value shown in Figures 1 and 2 remained constant at $0.1 \Omega$ for all measurements in this study. However, the value of capacitance was increased from 0 to $220 \mu \mathrm{F}$ to investigate changes in the motor current waveform and radiated sound pressure. Except for a capacitance of 0 , which represented the circuit without any capacitance, other entries represent the actual values of capacitance according to the capacitor. The actual value of capacitance connected to the motor power input was $100 \mu \mathrm{F}$ for all cases, if not described otherwise in present study. Very high spikes in current were shown when no capacitor was included, as in Figure 11a. One reason behind the decision to include a capacitor for motor input power was to remove such spikes in motor current measurements, to prevent aliasing when sampling at a rate of $44.1 \mathrm{kHz}$ was very low compared to the sharpness of spikes. However, a sampling rate of $44.1 \mathrm{kHz}$ is reasonably high enough for sound pressure measurement. Another reason was to reduce radiated sound pressure by removing spikes in the motor input current. Even by including the smallest capacitance, such as $10 \mu \mathrm{F}$, spikes in current measurement were significantly reduced, as shown in Figure 11b. Spikes in current measurement were further reduced as capacitance was increased, and the lowest spikes are shown in Figure $11 \mathrm{f}$ when a capacitance of $220 \mu \mathrm{F}$, the greatest in this research, was used. 


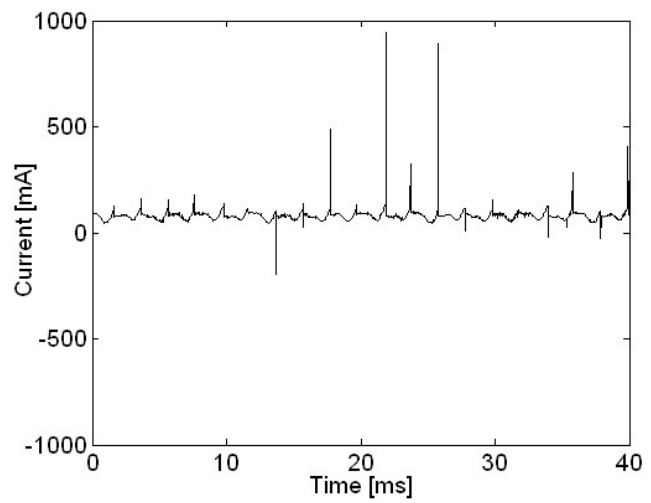

(a)

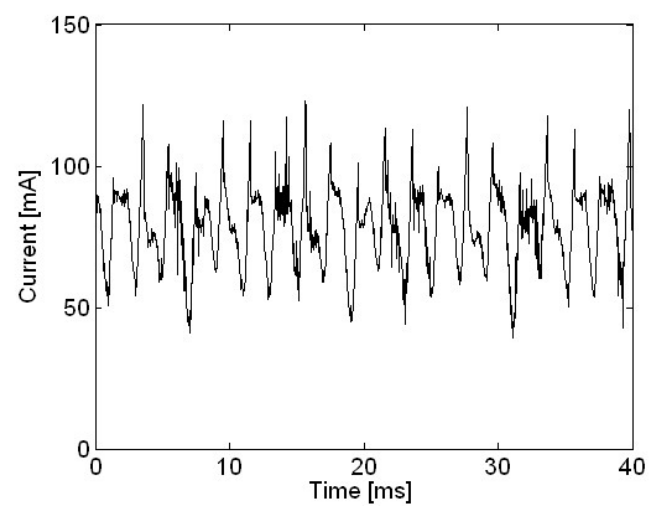

(c)

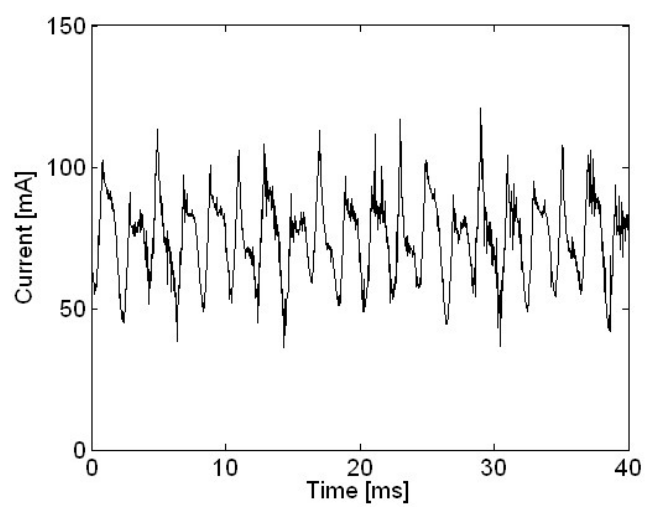

(e)

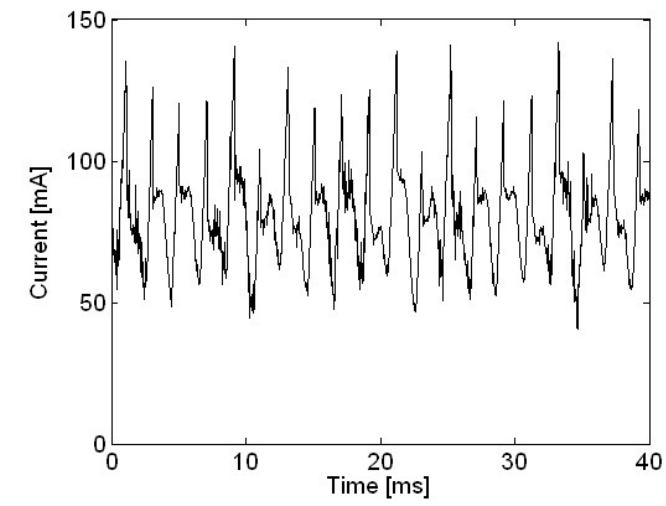

(b)

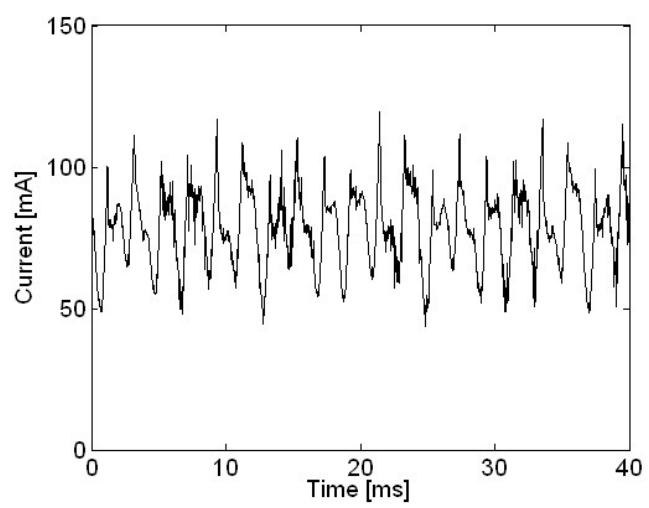

(d)

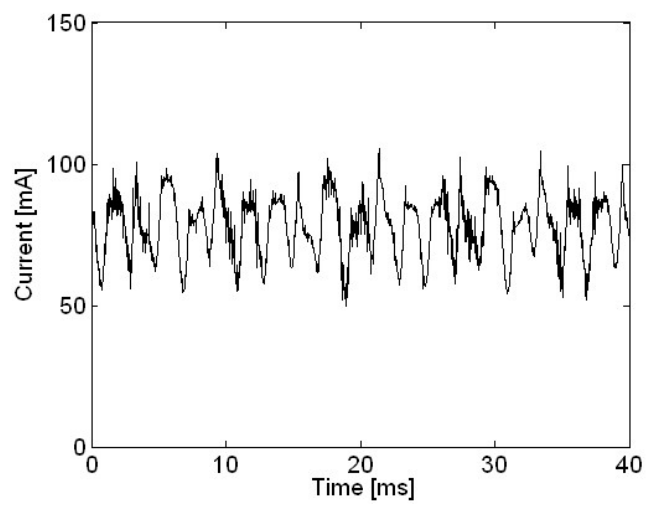

(f)

Figure 11. Motor current with various capacitances in the time domain: (a) 0; (b) $10 \mu \mathrm{F}$; (c) $33 \mu \mathrm{F}$; (d) $47 \mu \mathrm{F}$; (e) $100 \mu \mathrm{F}$; (f) $220 \mu \mathrm{F}$.

A relatively higher amplitude ratio between sound pressure and current measurement appeared below $1 \mathrm{kHz}$, around $1.4 \mathrm{kHz}$, above $5 \mathrm{kHz}$. The amplitude ratio was highest around $7.2 \mathrm{kHz}$ and represented modal resonances, as shown in Figure 10.

Motor current measurements with various capacitances in the frequency domain are shown in Figure 12. Current level at higher frequencies reduced as capacitance becomes higher, when compared with a current measurement at $10 \mu \mathrm{F}$ capacitance. However, little change occurred at two major frequencies with the two highest amplitudes, such as $500 \mathrm{~Hz}$ and $1000 \mathrm{~Hz}$ shown in Figure 12, as capacitance increased, except for at $220 \mu \mathrm{F}$. There was slightly more change in current level at these two major frequencies for capacitance of $220 \mu \mathrm{F}$ than for other, smaller capacitances. 


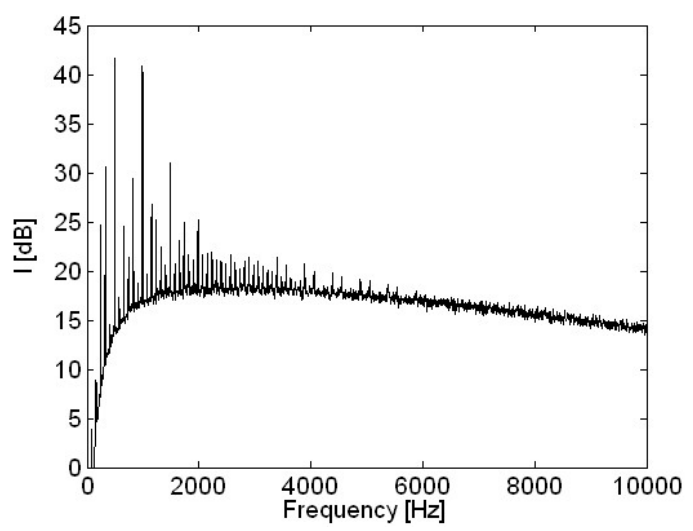

(a)

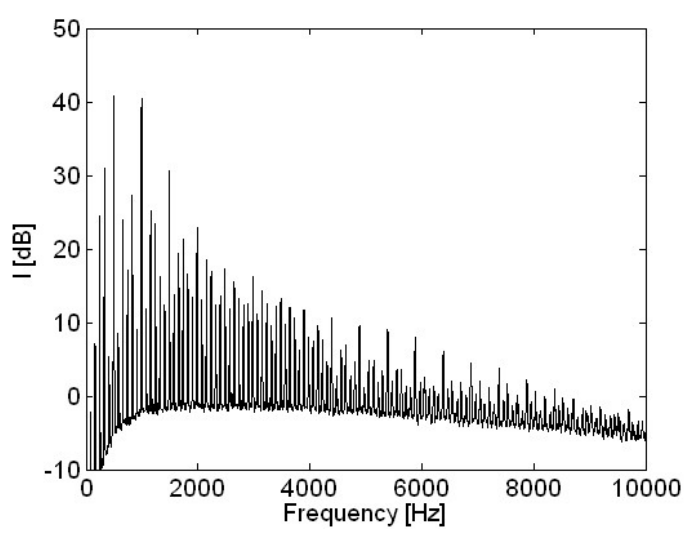

(c)

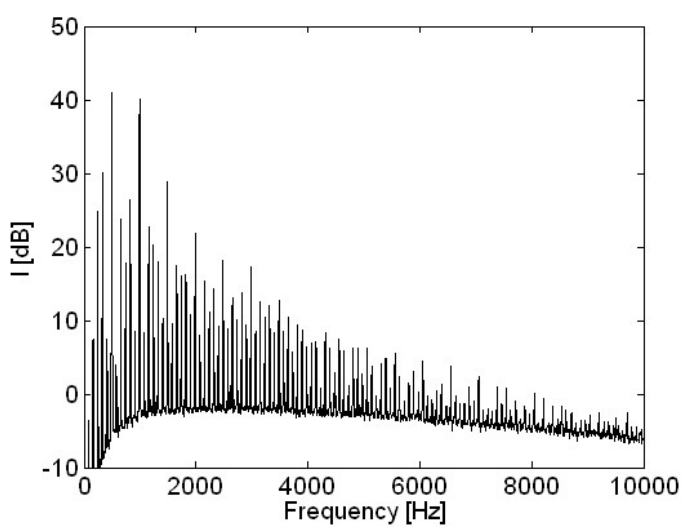

(e)

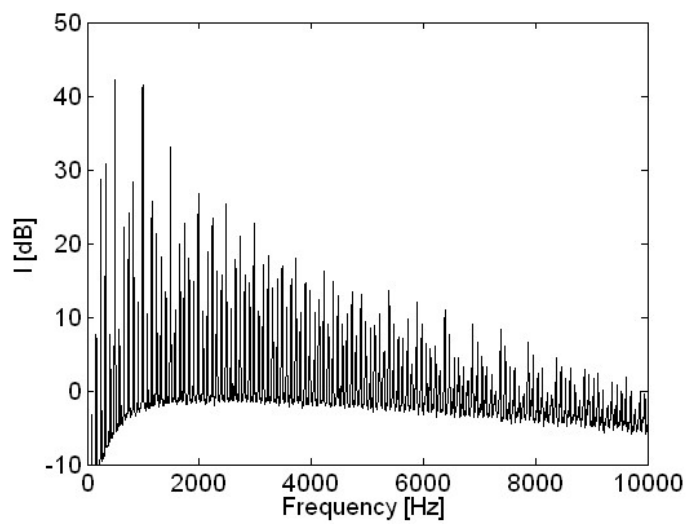

(b)

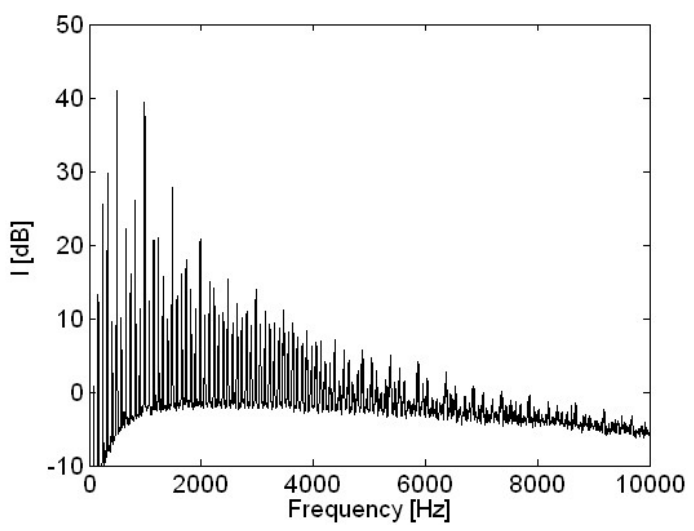

(d)

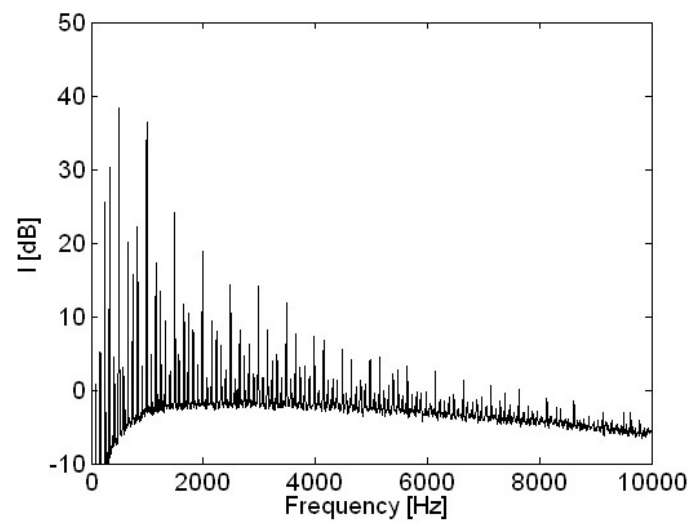

(f)

Figure 12. Motor current measurement with various capacitances in the frequency domain: (a) 0 ; (b) $10 \mu \mathrm{F}$; (c) $33 \mu \mathrm{F}$; (d) $47 \mu \mathrm{F}$; (e) $100 \mu \mathrm{F}$; (f) $220 \mu \mathrm{F}$.

The amplitude of the sound pressure measurement at the motor center with various capacitances is shown in Figure 13. However, significant changes in sound pressure level at the motor center with various capacitances was not clearly shown. The amplitude ratio for sound pressure at the motor center and motor current with various capacitances is shown in Figure 14. There was significant deviation in the amplitude ratio with various capacitances, but the highest peaks occurred at frequencies around $7 \mathrm{kHz}$ for all capacitances, as shown in Figure 14. 


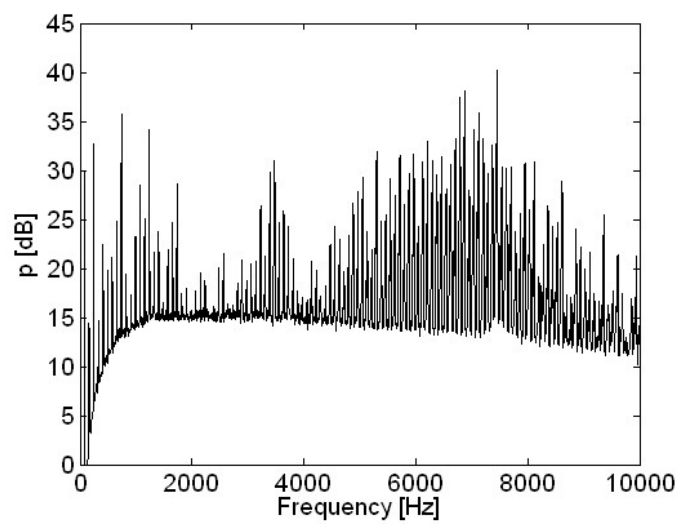

(a)

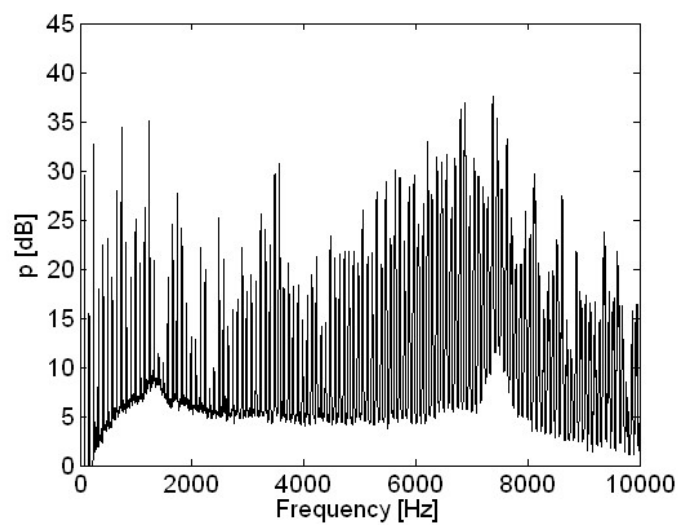

(c)

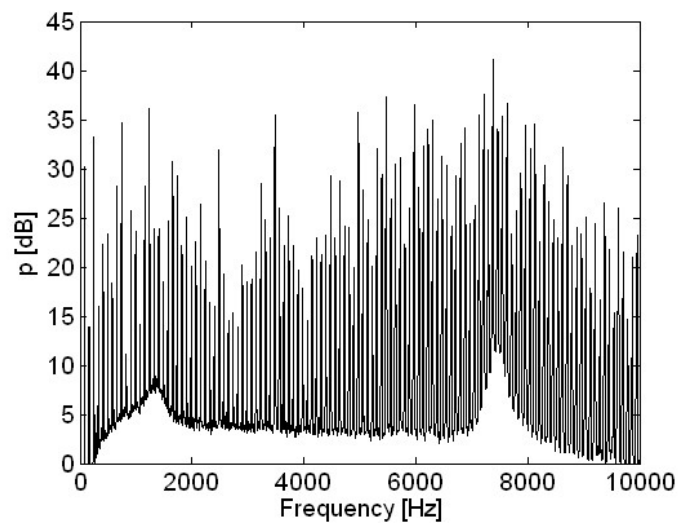

(e)

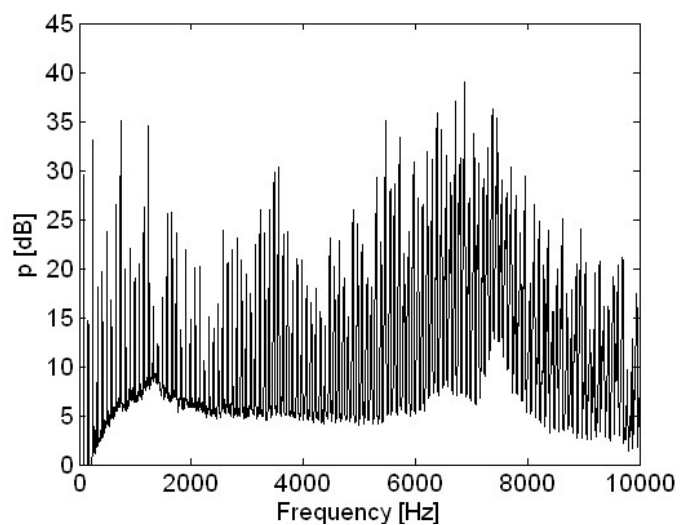

(b)

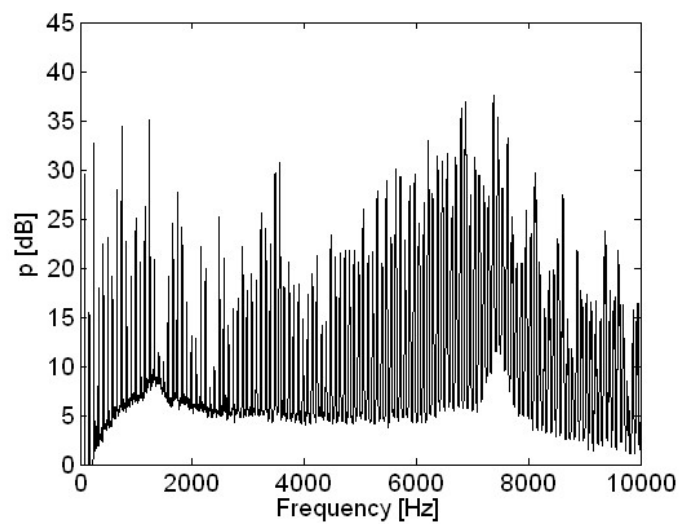

(d)

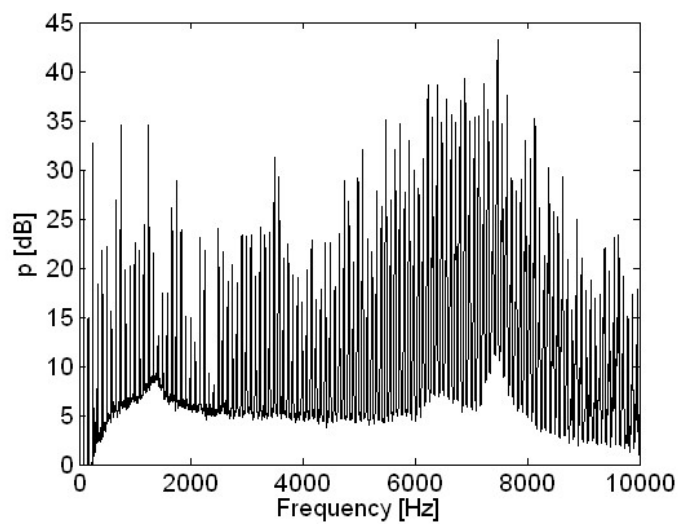

(f)

Figure 13. Amplitude of sound pressure at the motor center with various capacitances: (a) 0 ; (b) $10 \mu \mathrm{F}$; (c) $33 \mu \mathrm{F}$; (d) $47 \mu \mathrm{F}$; (e) $100 \mu \mathrm{F}$; (f) $220 \mu \mathrm{F}$.

Motor current, sound pressure, and the amplitude ratio for sound pressure and current for a motor rotating clock-wise (CW) with a $100 \mu \mathrm{F}$ capacitor are shown in Figure 15. Significant differences in motor current for opposite rotational directions were shown both in the time and frequency domains in Figures 11e and 15a and Figures 12e and 15b, respectively. One possible explanation for this difference in motor current given opposite rotational directions would be a deviation in the condition of brushes and commutators. Current and sound pressure levels for a motor with various capacitances, summed over the frequency range from 0 to $10 \mathrm{kHz}$, are shown in Table 1 . The four different measurement locations from P1 to P4 in Table 1 coincide with microphone locations from 1 to 4 as shown in 
Figure 1. The mean refers to the root-mean-square of sound pressure measurements in four positions for each capacitance. Here, the accuracy of the instrumentation should also be considered, which is typically more or less than one $\mathrm{dB}$. So, the decimal points in $\mathrm{AB}$ do not represent accuracy of the results. The ranking of sound pressure in terms of capacitance depended on the measurement location. Overall, the mean sound pressure with a capacitance of $47 \mu \mathrm{F}$ was slightly lower than that at $100 \mu \mathrm{F} ; 57.1 \mathrm{~dB}$ and $57.3 \mathrm{~dB}$, respectively. Mean sound pressure of $1.1 \mathrm{~dB}$ and $0.9 \mathrm{~dB}$ was reduced with capacitances of $47 \mu \mathrm{F}$ and $100 \mu \mathrm{F}$ when compared with sound pressure without a capacitor. However, even though the current level was further reduced by using a higher capacitance of $220 \mu \mathrm{F}$, mean sound pressure was not reduced when compared with sound pressure without a capacitor. Also, even though there were current level differences between CCW and CW motor rotational directions, mean sound pressure did not change due to motor rotational directions.

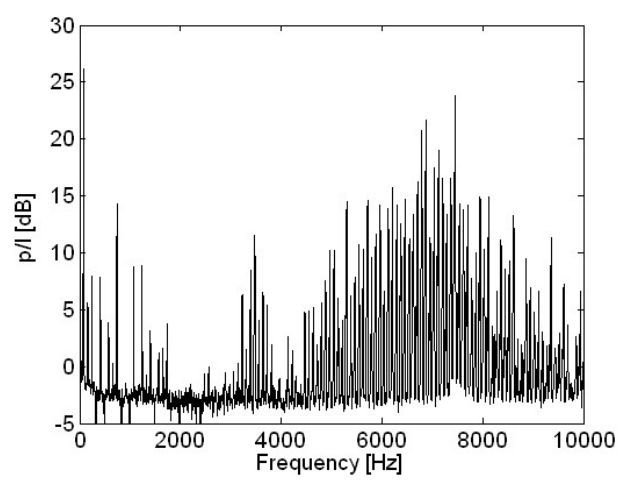

(a)

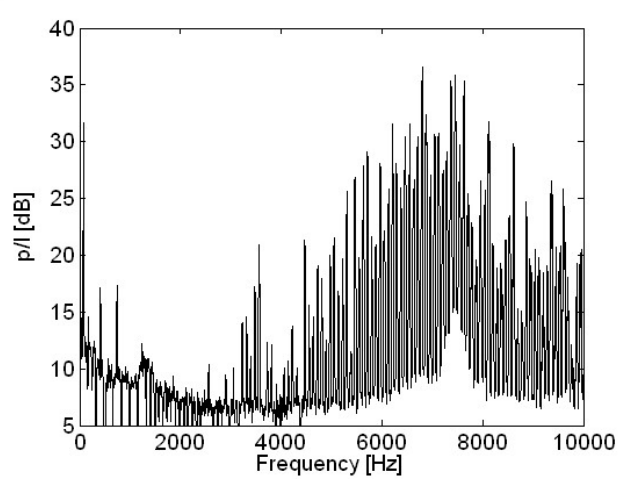

(c)

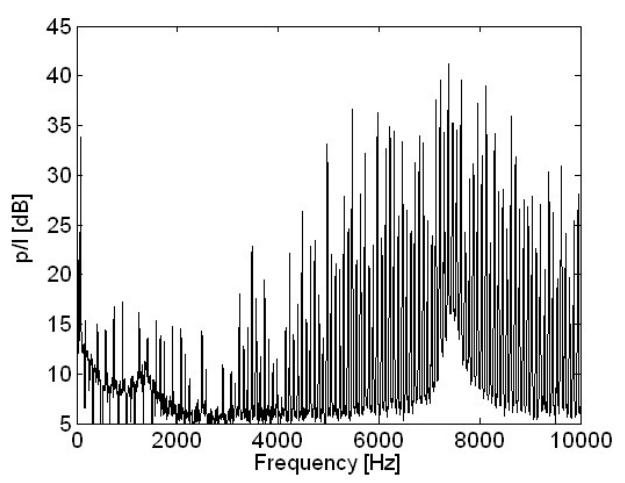

(e)

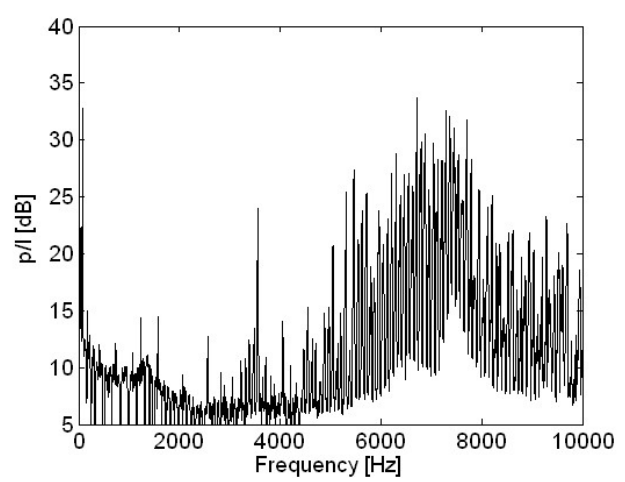

(b)

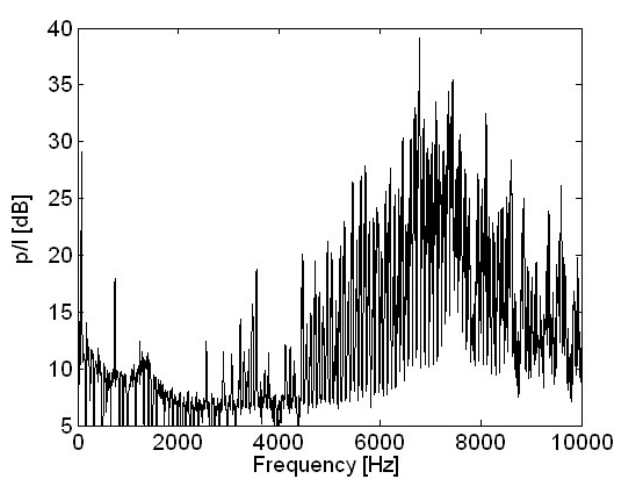

(d)

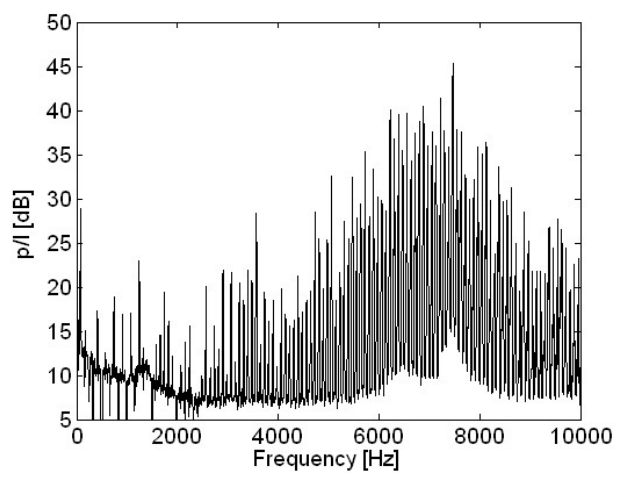

(f)

Figure 14. Amplitude ratio of sound pressure at the motor center and motor current with various capacitances: (a) 0; (b) $10 \mu \mathrm{F}$; (c) $33 \mu \mathrm{F}$; (d) $47 \mu \mathrm{F}$; (e) $100 \mu \mathrm{F}$; (f) $220 \mu \mathrm{F}$. 


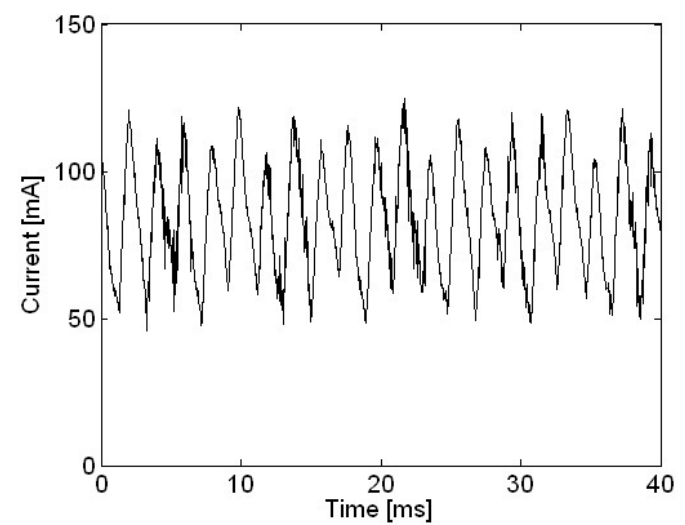

(a)

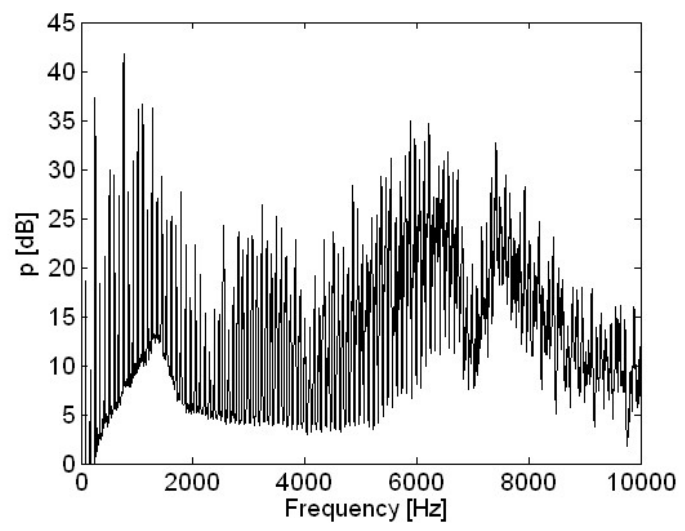

(c)

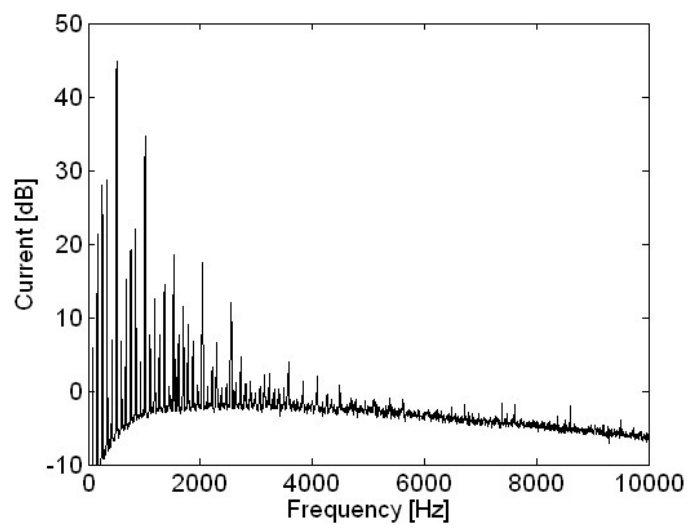

(b)

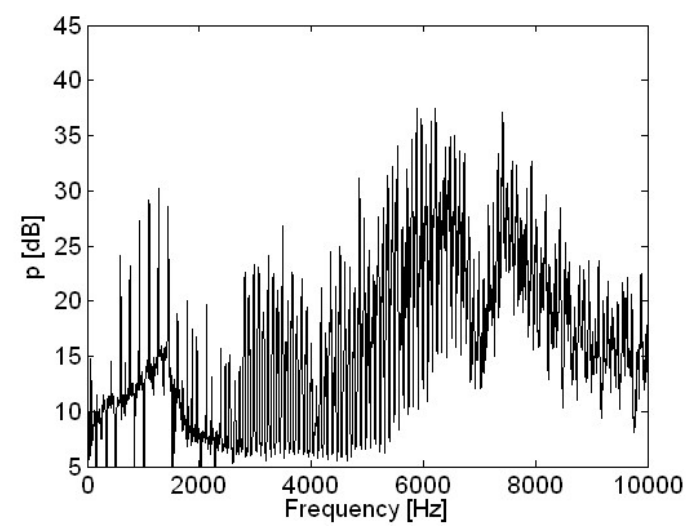

(d)

Figure 15. Motor rotating clock-wise with a $100 \mu \mathrm{F}$ capacitor: (a) current in the time domain; (b) current in the frequency domain; (c) sound pressure; (d) amplitude ratio of sound pressure and current.

Table 1. Current and sound level $(\mathrm{dB})$ of a motor with various capacitances.

\begin{tabular}{cccccccc}
\hline Capacitance & Direction & I & P1 & P2 & P3 & P4 & Mean \\
\hline 0 & CCW & 52.5 & 61.8 & 58.3 & 55.1 & 51.3 & 58.2 \\
$10 \mu \mathrm{F}$ & CCW & 48.7 & 61.5 & 58.3 & 54.0 & 48.7 & 57.8 \\
$33 \mu \mathrm{F}$ & CCW & 47.2 & 61.5 & 58.2 & 53.8 & 48.7 & 57.8 \\
$47 \mu \mathrm{F}$ & CCW & 46.5 & 61.4 & 56.2 & 52.9 & 48.1 & 57.1 \\
$100 \mu \mathrm{F}$ & CCW & 46.8 & 61.6 & 55.2 & 54.1 & 50.9 & 57.3 \\
$220 \mu \mathrm{F}$ & CCW & 44.1 & 61.6 & 58.6 & 55.5 & 49.9 & 58.2 \\
$100 \mu \mathrm{F}$ & $\mathrm{CW}$ & 48.3 & 61.5 & 55.0 & 54.4 & 51.1 & 57.3 \\
\hline
\end{tabular}

The particle velocity of the motor housing surface was reconstructed using SONAH and is shown in Figures 16-21. All reconstructed particle velocity data in this study was based on A-weighted measurement pressure. Results from four different types of references (current measurement, a moving reference at the motor center, a moving reference on top of the motor, and an auto moving reference) are shown for twelve frequencies. Results from the moving references were estimated using Equation (14) by combining current and sound pressure measurements using scanning microphones at moving reference locations. The moving reference locations coincided with scanning microphone positions as shown in Figure 1. The auto moving reference was a special case described in this research, and each measurement from a scanning microphone was considered as a moving reference. Reconstructed particle velocity based on different types of references was relatively similar for most frequencies and agreed very well for low frequencies. However, deviations between reconstructed particle velocities 
using different types of references are shown at $996 \mathrm{~Hz}$ in Figure 18. It was challenging to judge which reference type was best at $996 \mathrm{~Hz}$ alone, even though some response of the motor housing due to electro-magnetic forces was shown for all four reference types. Also, deviations between reconstructed particle velocities using different types of references are shown at $1328 \mathrm{~Hz}$ in Figure 19. Reconstructed particle velocity using moving reference 3, located at the motor center, provides a visualization of motor internal resonance that is slightly more clear than from other reference types. Reconstructed particle velocities from different types of references were similar except for the results of the auto moving reference, which was dominated by a reflection from the base plate at $1736 \mathrm{~Hz}$. These similar reconstructed particle velocities provided clear visualizations of $n=2$ mode at the bottom of the motor housing at $4988 \mathrm{~Hz}$ [6]. Which reference type was best at $5072 \mathrm{~Hz}$ alone was not obvious, even though some response of the motor housing due to electro-magnetic forces at the bottom of the motor housing was shown for all four reference types. Reconstructed particle velocity using moving reference 3 , located at the motor center, provided a visualization of $n=2$ mode at the center of the motor housing that was slightly more clear than that of other reference types at $7208 \mathrm{~Hz}$. A summary of source particle velocity reconstruction is provided in Table 2 . Reconstructed particle velocities based on different types of references were relatively similar for the twelve frequencies shown, with some exceptions, especially at the highest frequency and frequencies corresponding to internal resonance of the motor.

Sound pressure measurements were taken with the motor rotating CW. The motor was powered to rotate in the opposite direction by switching the poles of the motor power input. The particle velocity of the motor housing surface while rotating $\mathrm{CW}$ was reconstructed using SONAH, and is shown in Figure 22. There was a slight deviation in motor rotational speed, $4960 \mathrm{rpm}$ and $5080 \mathrm{rpm}$ for CCW and CW, when the motor was rotating in different directions, with the power supply output voltage kept the same at $12 \mathrm{~V}$. Reconstructed particle velocity using moving reference 3 , located at the motor center, provided a visualization of the motor's internal resonance that was slightly clearer than that of other reference types, based on reconstructed particle velocity of the motor housing surface at $5120 \mathrm{~Hz}$ and $7172 \mathrm{~Hz}$.

The mean sound pressure measurement level for both in space and at frequencies above 0 to $10 \mathrm{kHz}$ was estimated for motor rotational directions of CCW and CW. The mean of A-weighted measurement pressure was $58.9 \mathrm{~dB}$ and $58.6 \mathrm{~dB}$, for $\mathrm{CCW}$ and $\mathrm{CW}$. However, the mean of measurement pressure without weighting (with linear weighting) was $72.1 \mathrm{~dB}$ for both CCW and CW.

Table 2. Description of source particle velocity reconstruction.

\begin{tabular}{ccc}
\hline Frequency & Order & Description of Source \\
\hline $80 \mathrm{~Hz}$ & $1 \mathrm{st} f_{\mathrm{r}}$ & Unbalanced force \\
$244 \mathrm{~Hz}$ & 3rd $f_{\mathrm{r}}, 1 \mathrm{st} f_{\mathrm{e}}$ & Top ventilation \\
$496 \mathrm{~Hz}$ & 6th $f_{\mathrm{r}}, 2$ nd $f_{\mathrm{e}}$ & Electro-magnetic force \\
$744 \mathrm{~Hz}$ & $9 \operatorname{th} f_{\mathrm{r}}, 3 \mathrm{rd} f_{\mathrm{e}}$ & Electro-magnetic force \\
$996 \mathrm{~Hz}$ & $12 \operatorname{th} f_{\mathrm{r}}, 4 \operatorname{th} f_{\mathrm{e}}$ & Electro-magnetic force \\
$1244 \mathrm{~Hz}$ & $15 \operatorname{th} f_{\mathrm{r}}, 5 \operatorname{th} f_{\mathrm{e}}$ & Electro-magnetic force \\
$1328 \mathrm{~Hz}$ & $16 \mathrm{th} f_{\mathrm{r}}$ & Internal resonance \\
$1736 \mathrm{~Hz}$ & $21 \mathrm{st} f_{\mathrm{r}}, 7 \operatorname{th} f_{\mathrm{e}}$ & Electro-magnetic force \\
$4988 \mathrm{~Hz}$ & $60 \operatorname{th} f_{\mathrm{r}}, 20 \operatorname{th} f_{\mathrm{e}}$ & Housing bottom $n=2$ mode \\
$5072 \mathrm{~Hz}$ & $61 \operatorname{th} f_{\mathrm{r}}$ & Internal resonance \\
$7208 \mathrm{~Hz}$ & 87th $f_{\mathrm{r}}, 29 \operatorname{th} f_{\mathrm{e}}$ & Housing center $n=2$ mode \\
\hline
\end{tabular}




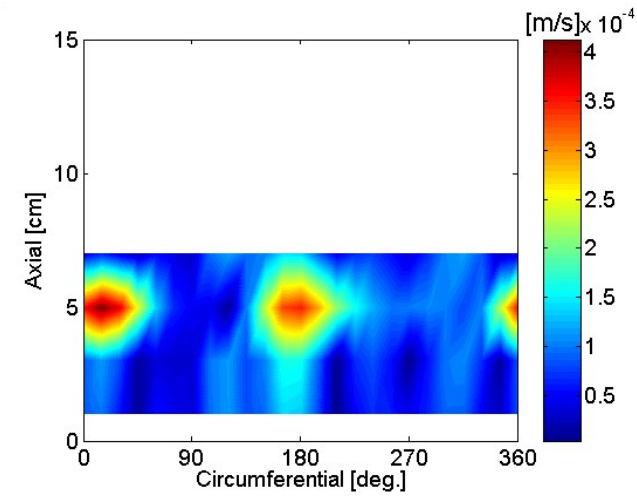

(a)

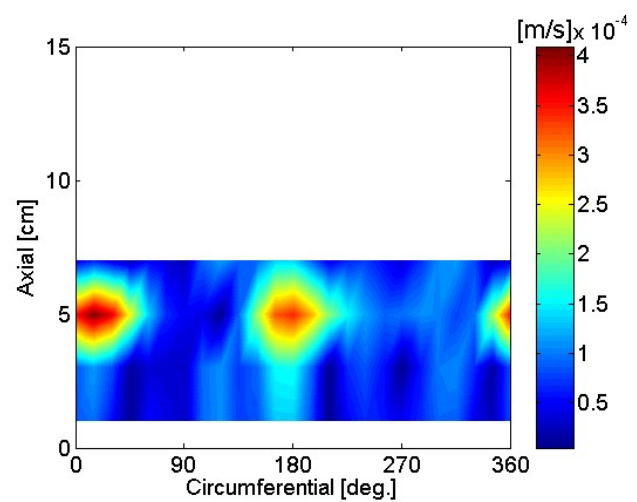

(c)

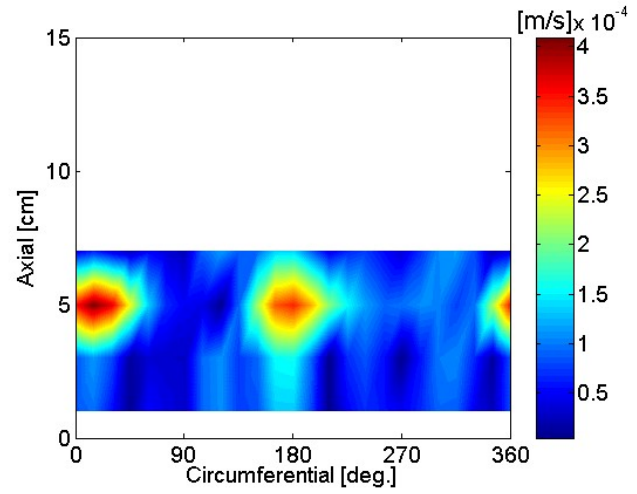

(e)

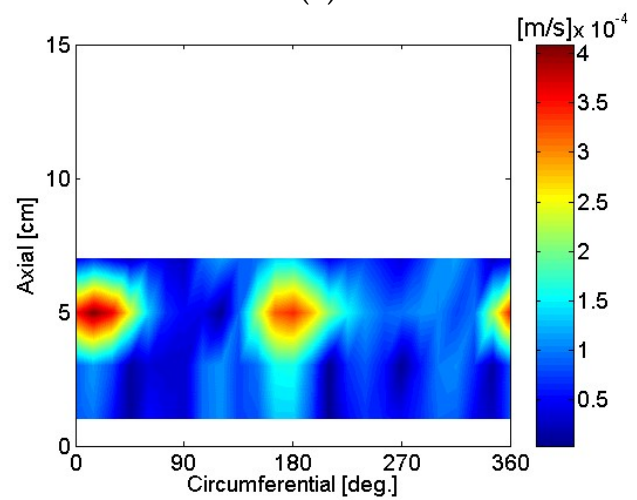

(g)

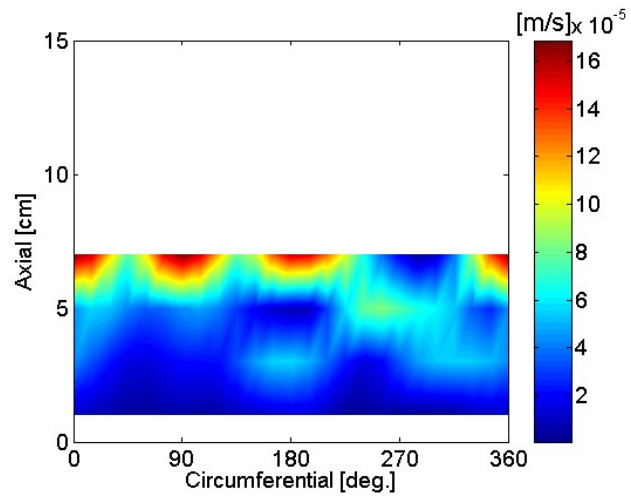

(b)

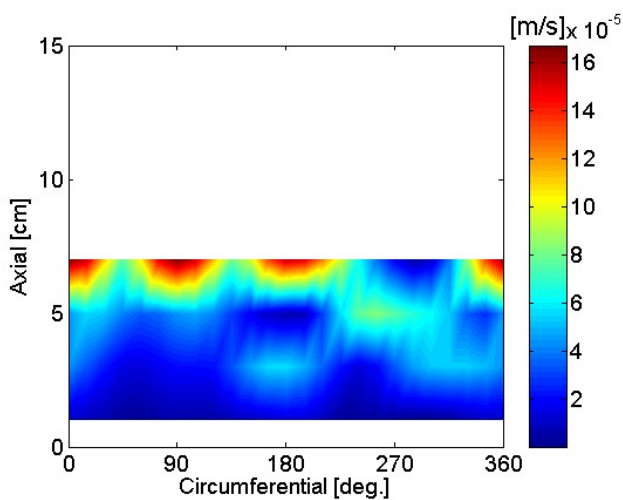

(d)

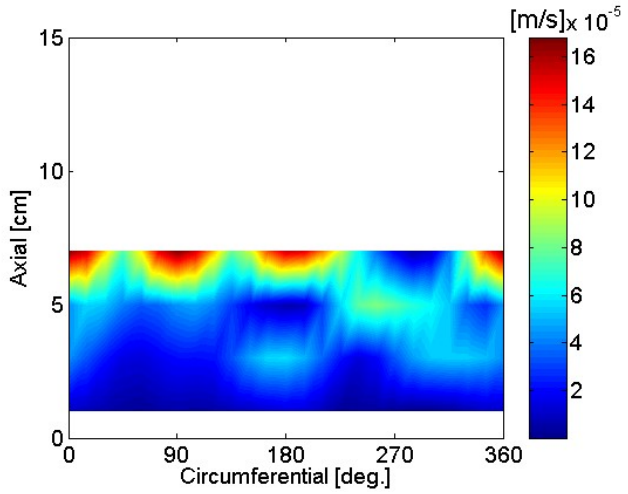

(f)

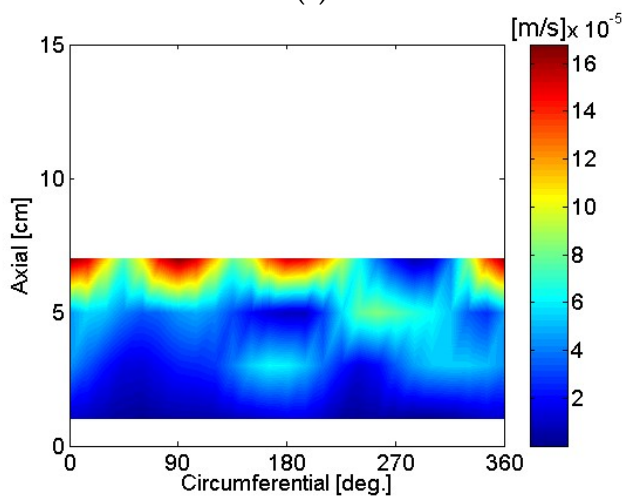

(h)

Figure 16. Particle velocity of the motor: (a) $80 \mathrm{~Hz}$, current reference; (b) $244 \mathrm{~Hz}$, current reference; (c) $80 \mathrm{~Hz}$, moving reference 3; (d) $244 \mathrm{~Hz}$, moving reference 3; (e) $80 \mathrm{~Hz}$, moving reference 4; (f) $244 \mathrm{~Hz}$, moving reference 4; (g) $80 \mathrm{~Hz}$, auto moving reference; (h) $244 \mathrm{~Hz}$, auto moving reference. 


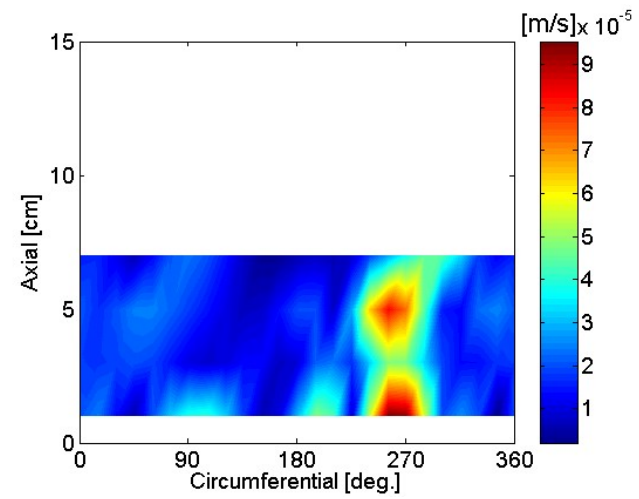

(a)

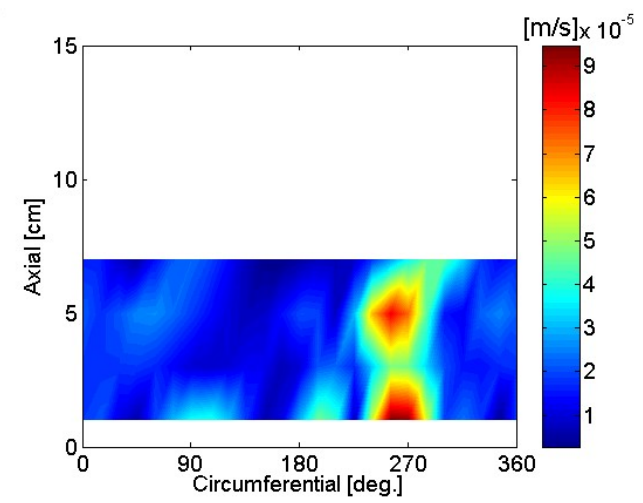

(c)

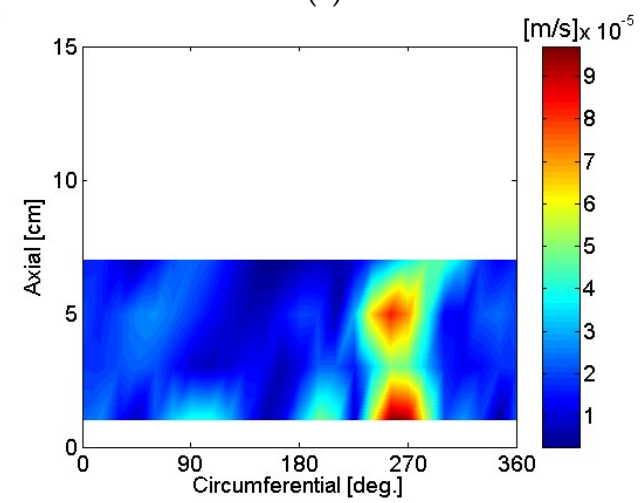

(e)

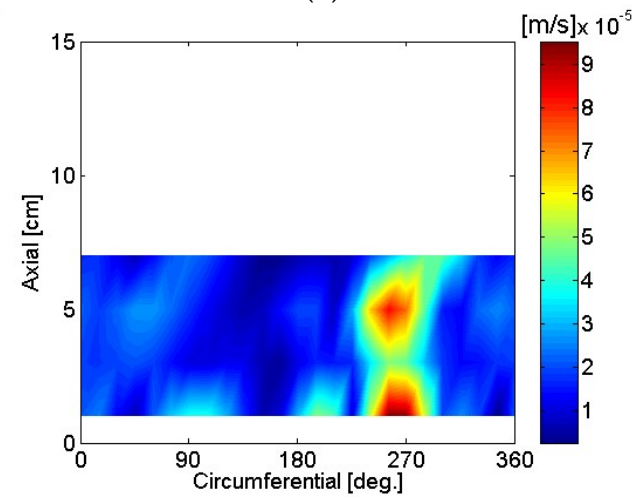

(g)

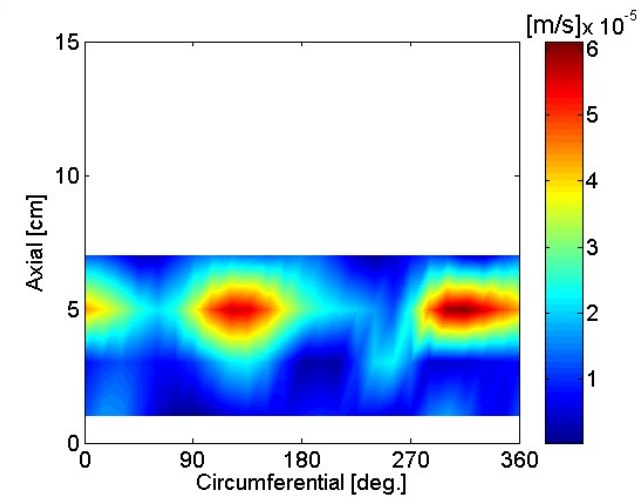

(b)

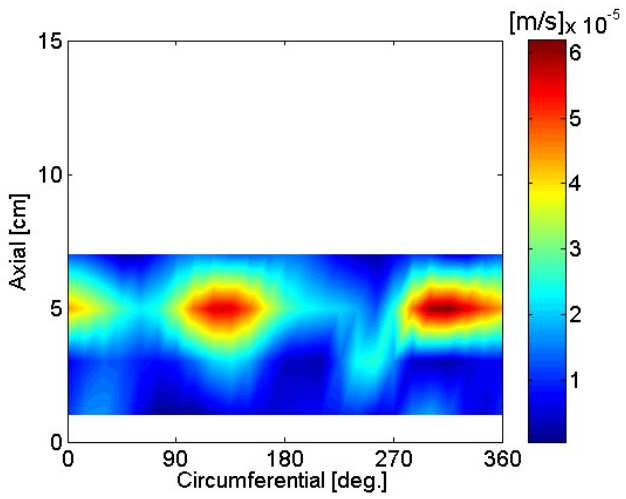

(d)

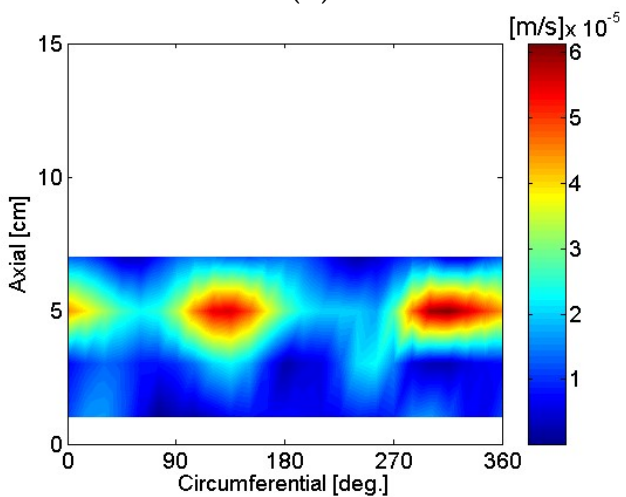

(f)

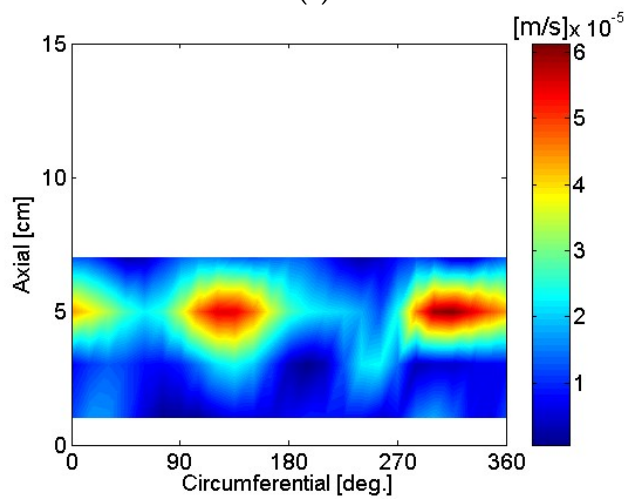

(h)

Figure 17. Particle velocity of the motor: (a) $496 \mathrm{~Hz}$, current reference; (b) $744 \mathrm{~Hz}$, current reference; (c) $496 \mathrm{~Hz}$, moving reference 3; (d) $744 \mathrm{~Hz}$, moving reference 3; (e) $496 \mathrm{~Hz}$, moving reference 4; (f) $744 \mathrm{~Hz}$, moving reference 4 ; (g) $496 \mathrm{~Hz}$, auto moving reference; (h) $744 \mathrm{~Hz}$, auto moving reference. 


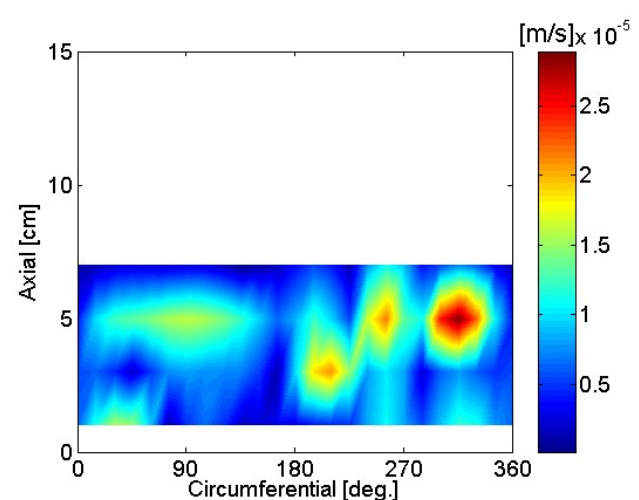

(a)

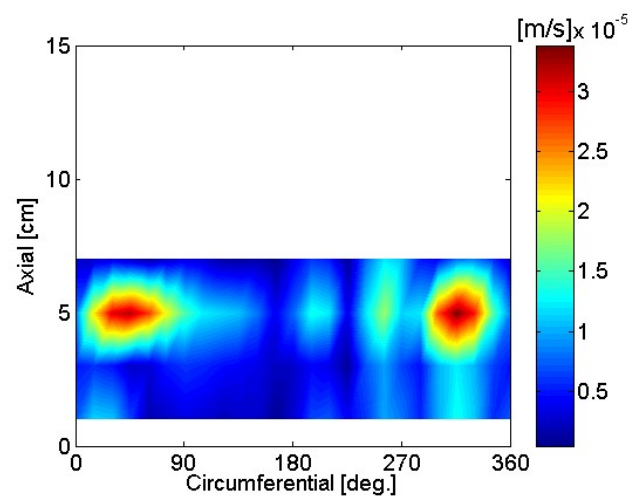

(c)

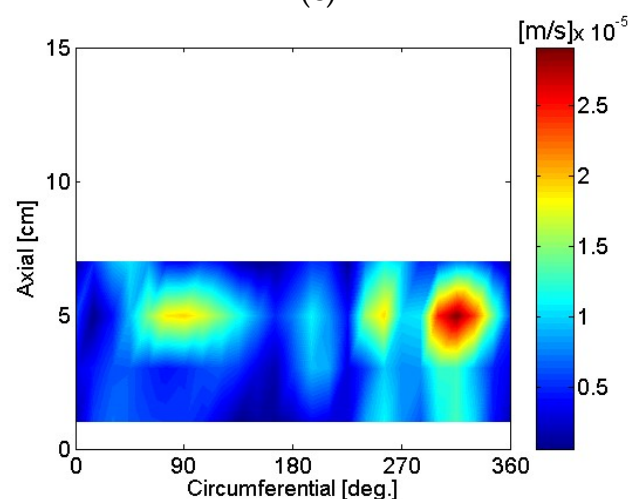

(e)

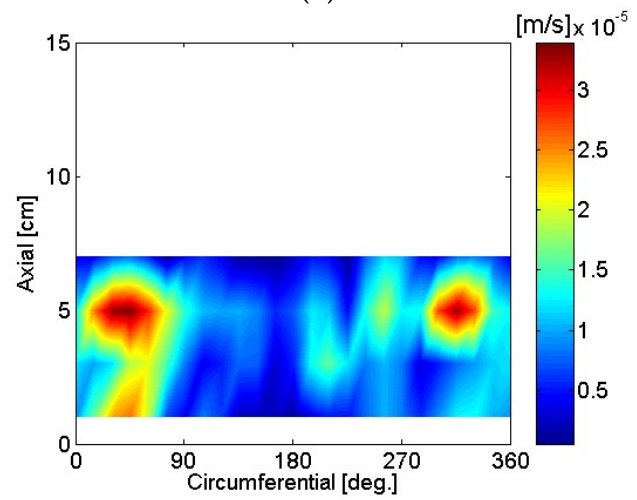

(g)

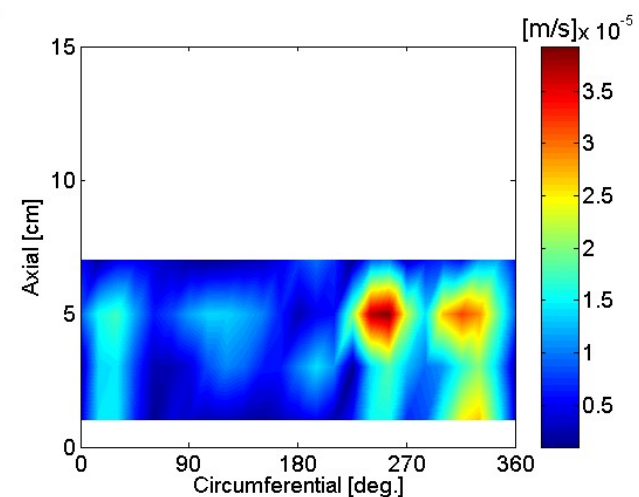

(b)

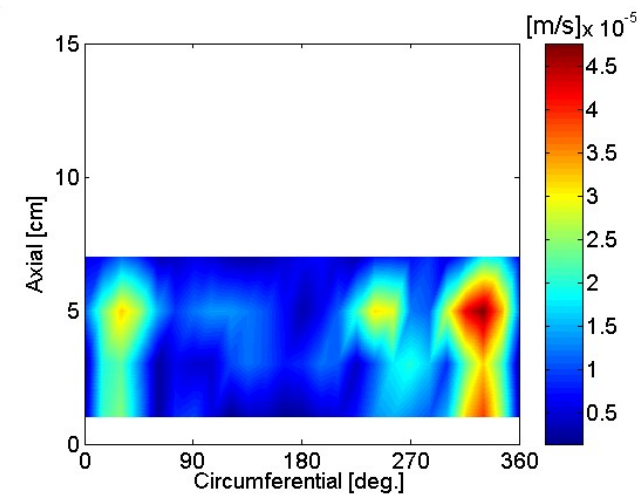

(d)

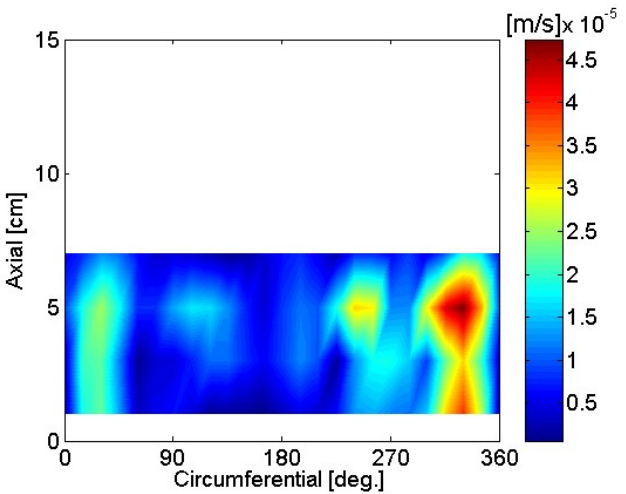

(f)

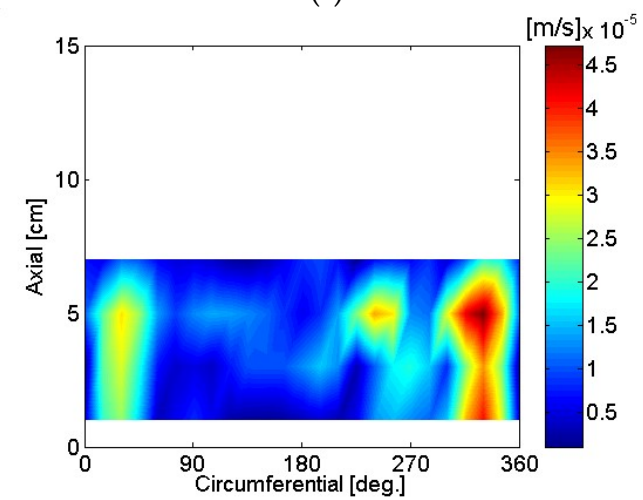

(h)

Figure 18. Particle velocity of the motor: (a) $996 \mathrm{~Hz}$, current reference; (b) $1244 \mathrm{~Hz}$, current reference; (c) $996 \mathrm{~Hz}$, moving reference 3; (d) $1244 \mathrm{~Hz}$, moving reference 3; (e) $996 \mathrm{~Hz}$, moving reference 4; (f) $1244 \mathrm{~Hz}$, moving reference 4; (g) $996 \mathrm{~Hz}$, auto moving reference; (h) $1244 \mathrm{~Hz}$, auto moving reference. 


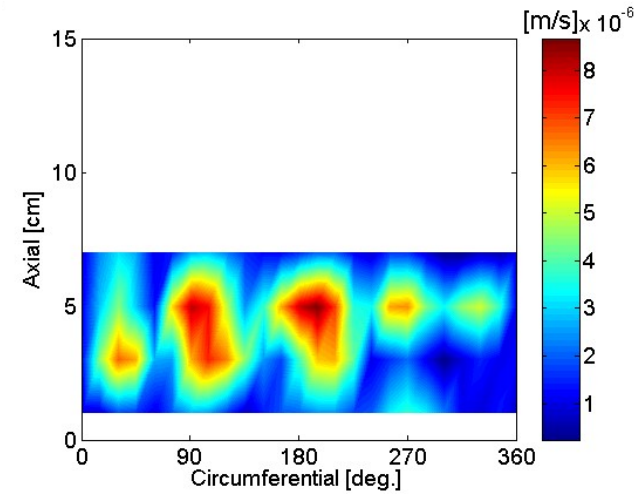

(a)

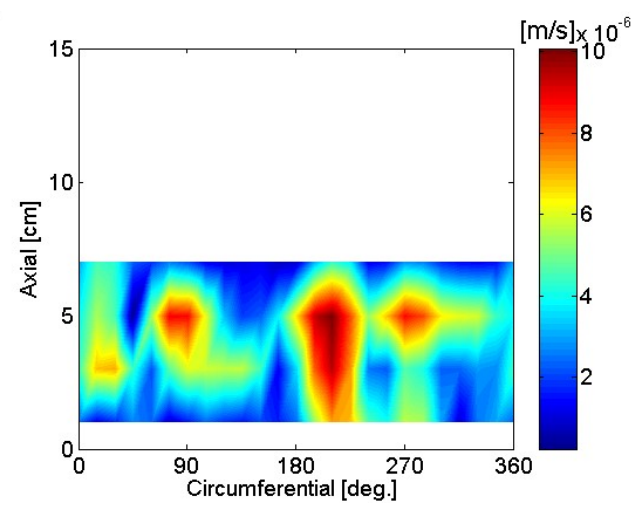

(c)

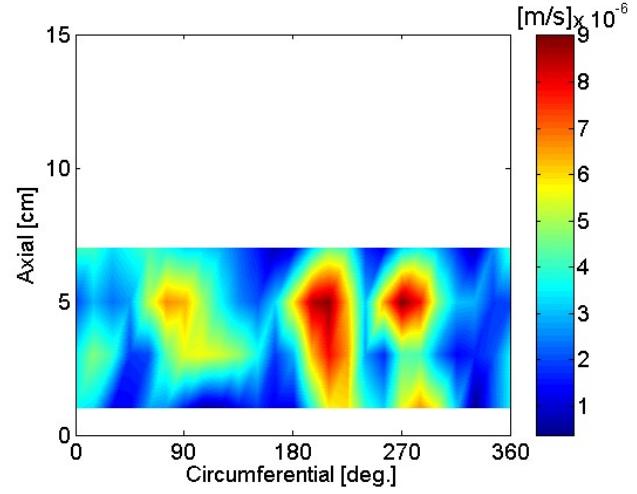

(e)

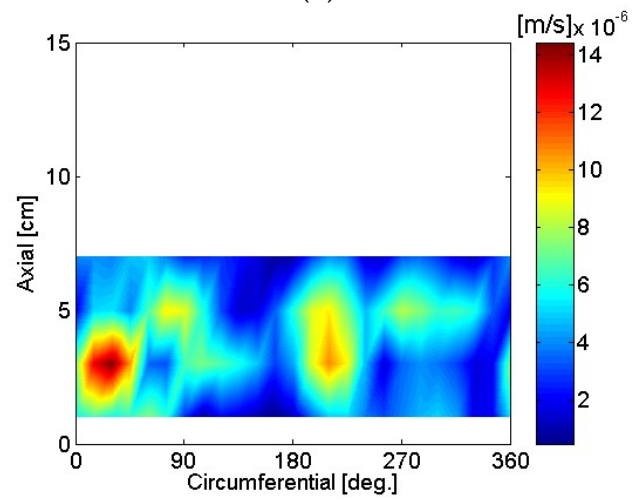

(g)

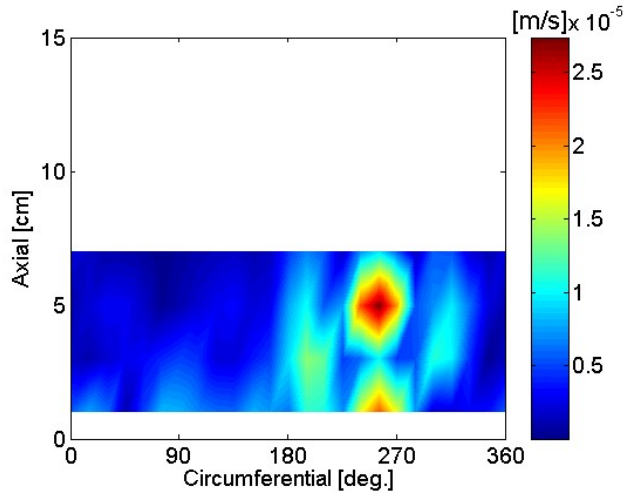

(b)

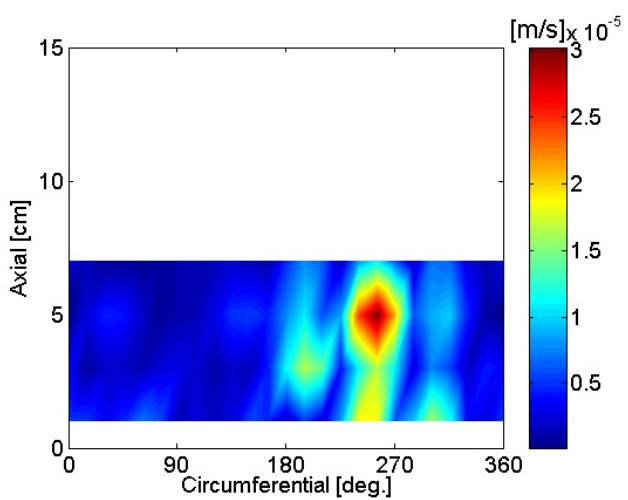

(d)

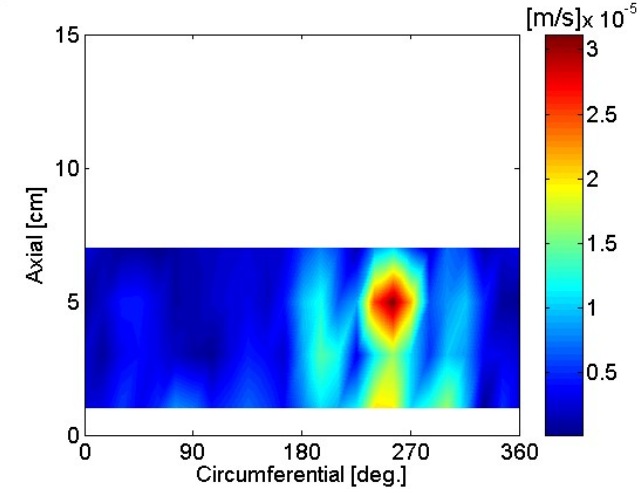

(f)

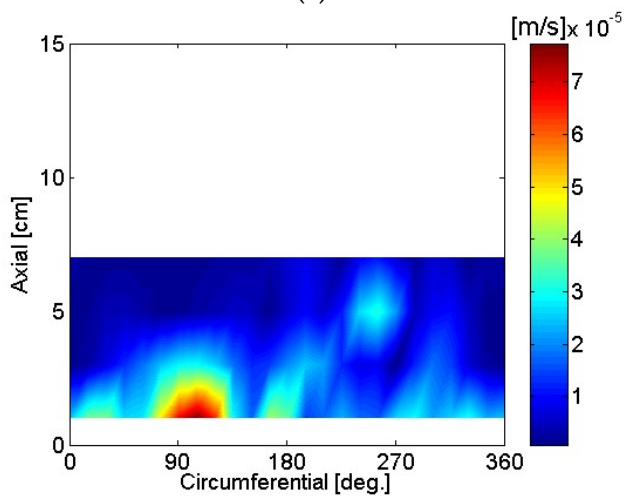

(h)

Figure 19. Particle velocity of the motor: (a) $1328 \mathrm{~Hz}$, current reference; (b) $1736 \mathrm{~Hz}$, current reference; (c) $1328 \mathrm{~Hz}$, moving reference 3; (d) $1736 \mathrm{~Hz}$, moving reference 3; (e) $1328 \mathrm{~Hz}$, moving reference 4; (f) $1736 \mathrm{~Hz}$, moving reference 4 ; (g) $1328 \mathrm{~Hz}$, auto moving reference; (h) $1736 \mathrm{~Hz}$, auto moving reference. 


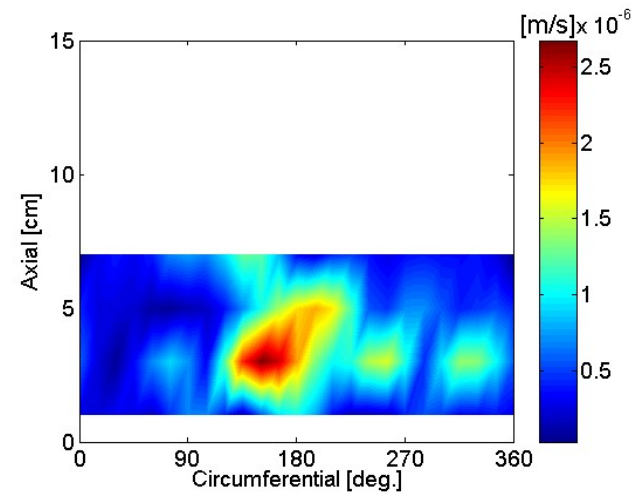

(a)

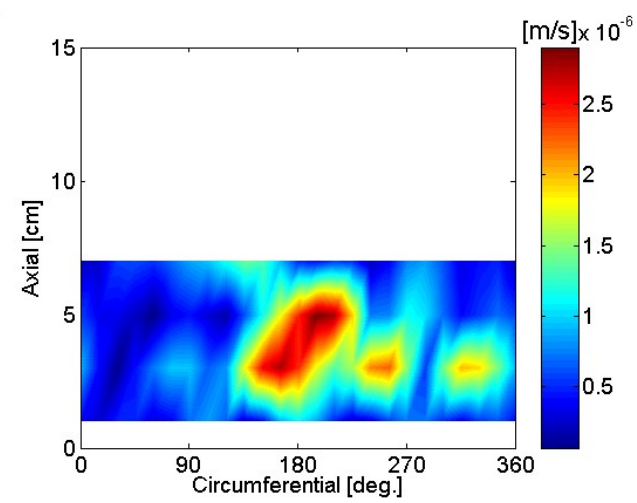

(c)

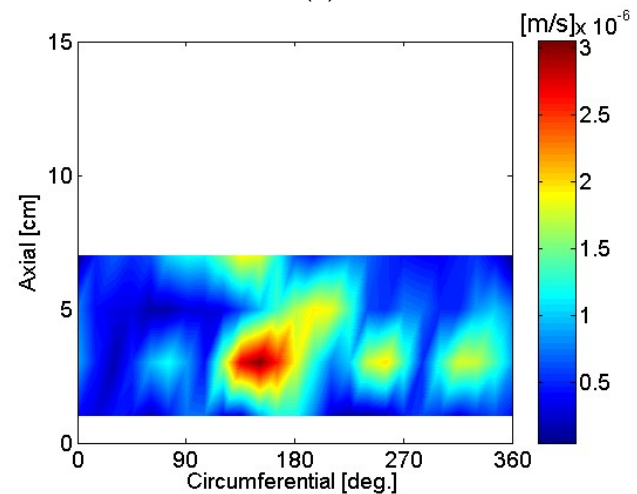

(e)

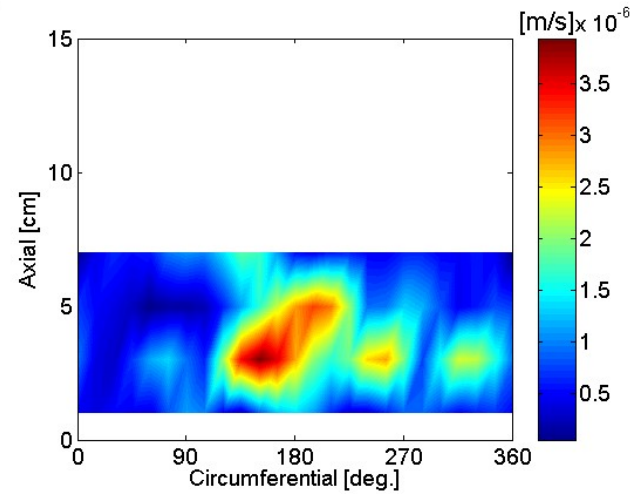

(g)

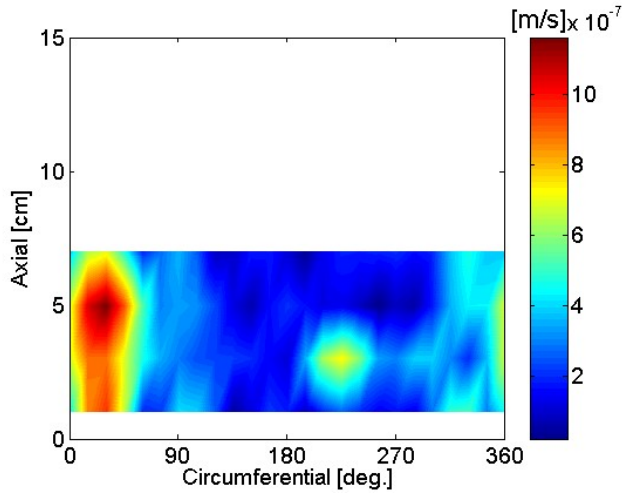

(b)

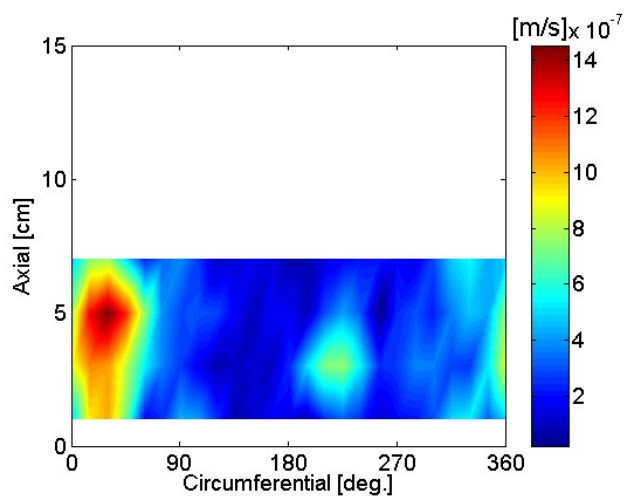

(d)

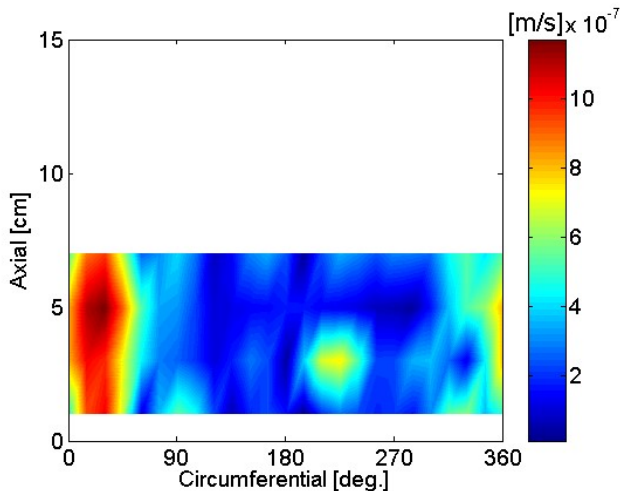

(f)

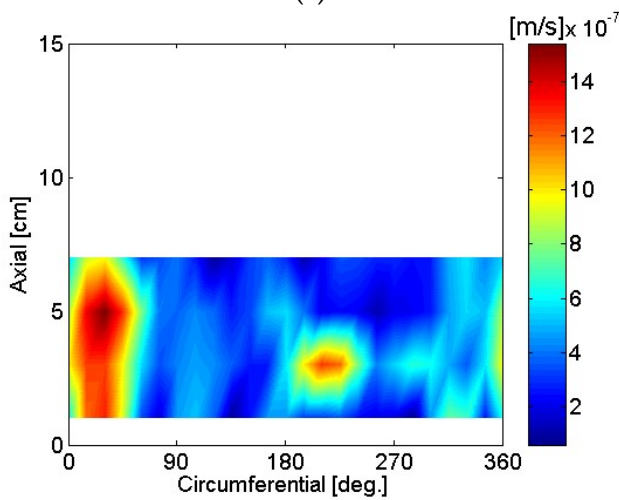

(h)

Figure 20. Particle velocity of the motor: (a) $4988 \mathrm{~Hz}$, current reference; (b) $5048 \mathrm{~Hz}$, current reference; (c) $4988 \mathrm{~Hz}$, moving reference 3; (d) $5048 \mathrm{~Hz}$, moving reference 3; (e) $4988 \mathrm{~Hz}$, moving reference 4; (f) $5048 \mathrm{~Hz}$, moving reference 4; (g) $4988 \mathrm{~Hz}$, auto moving reference; (h) $5048 \mathrm{~Hz}$, auto moving reference. 


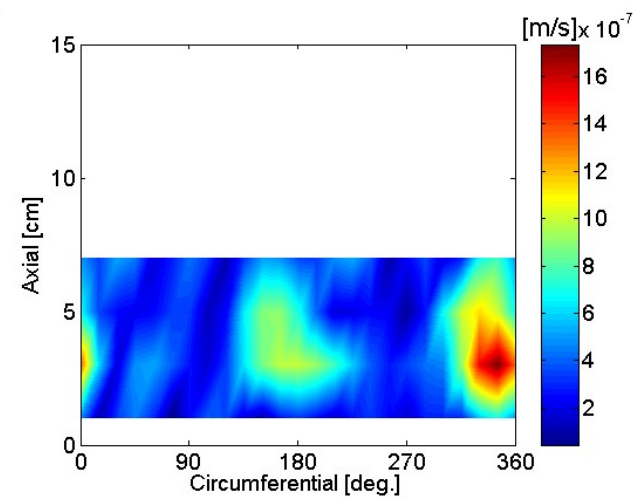

(a)

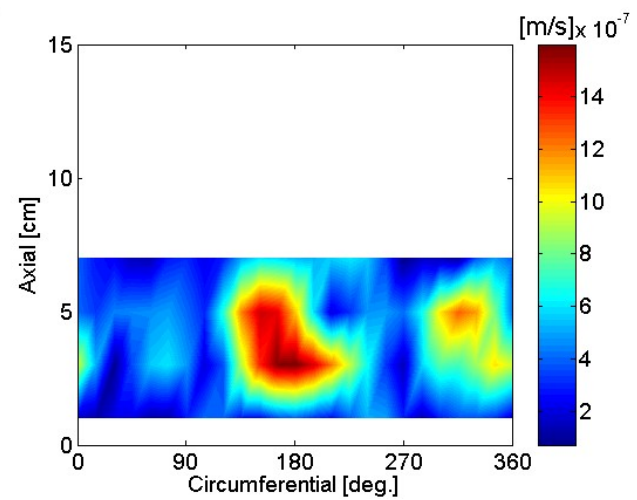

(c)

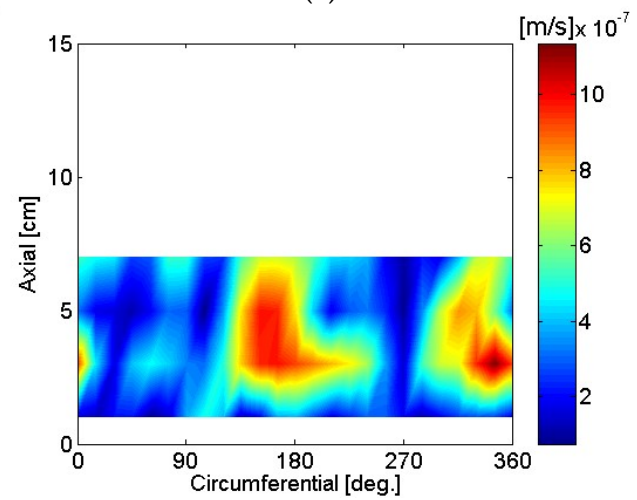

(e)

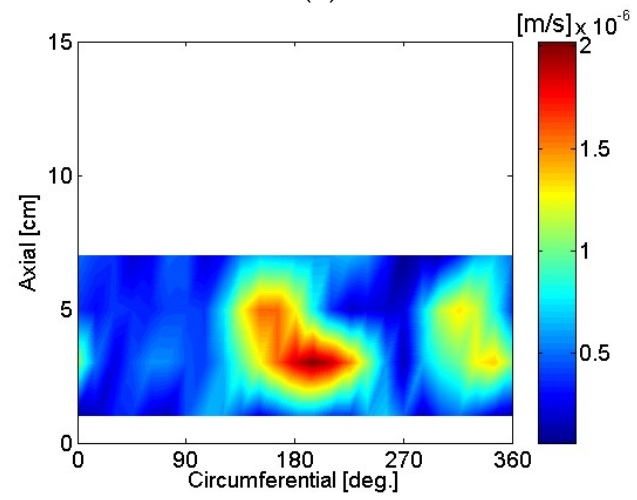

(g)

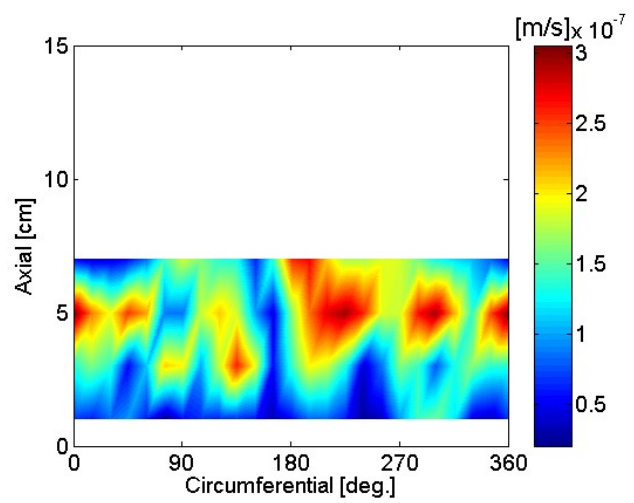

(b)

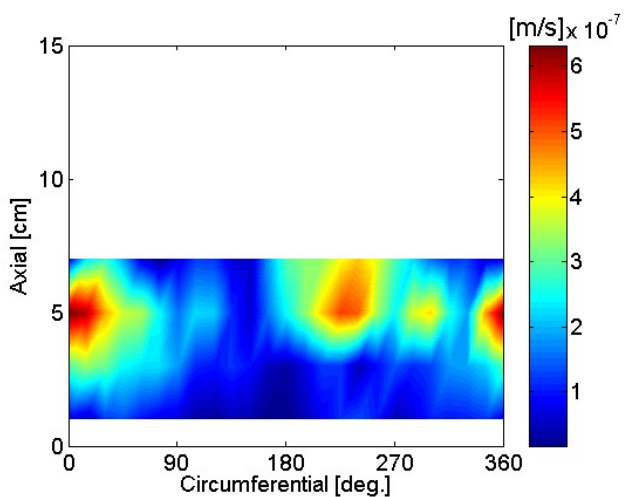

(d)

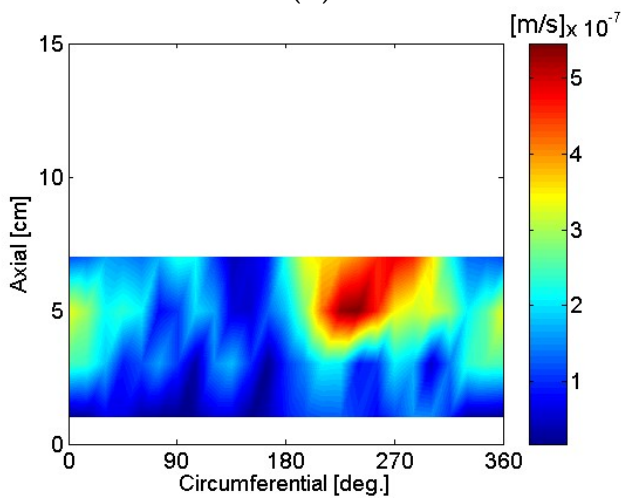

(f)

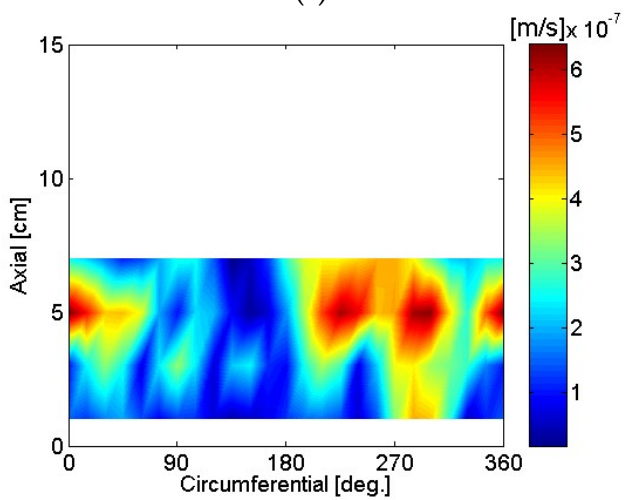

(h)

Figure 21. Particle velocity of the motor: (a) $5072 \mathrm{~Hz}$, current reference; (b) $7208 \mathrm{~Hz}$, current reference; (c) $5072 \mathrm{~Hz}$, moving reference 3; (d) $7208 \mathrm{~Hz}$, moving reference 3; (e) $5072 \mathrm{~Hz}$, moving reference 4; (f) $7208 \mathrm{~Hz}$, moving reference 4; (g) $5072 \mathrm{~Hz}$, auto moving reference; (h) $7208 \mathrm{~Hz}$, auto moving reference. 


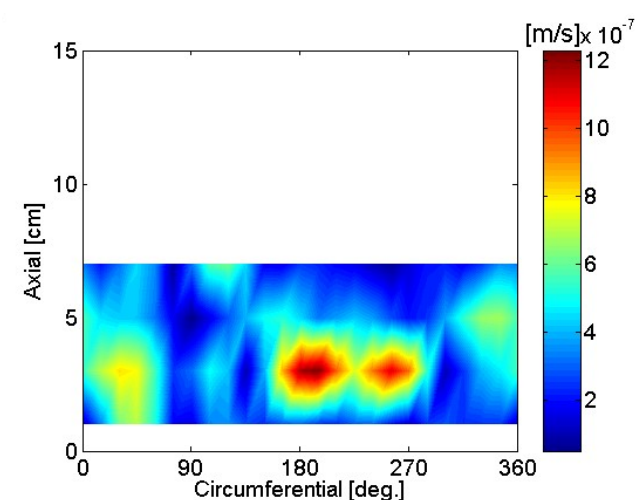

(a)

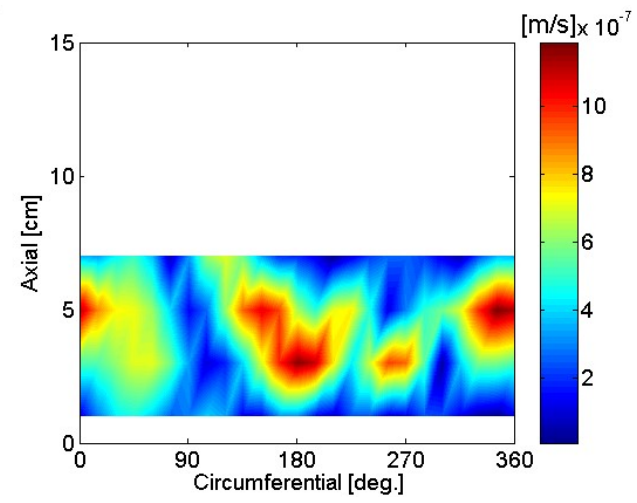

(c)

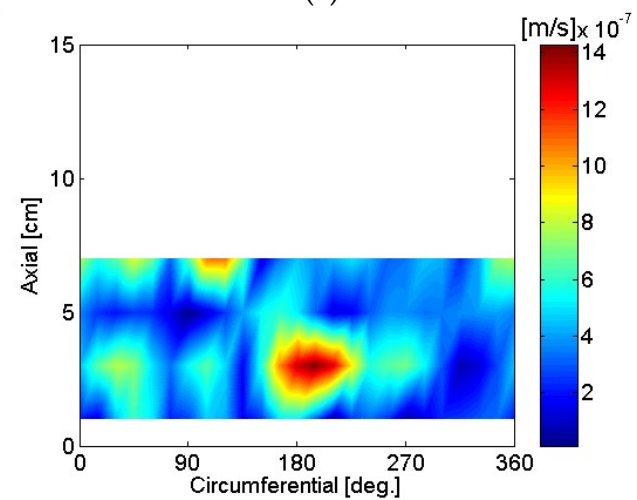

(e)

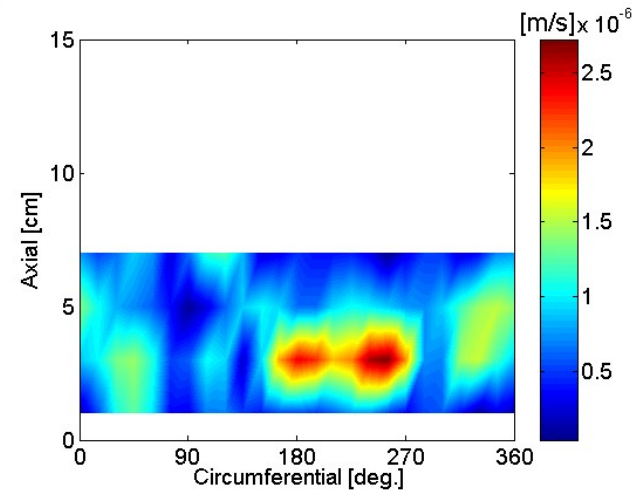

(g)

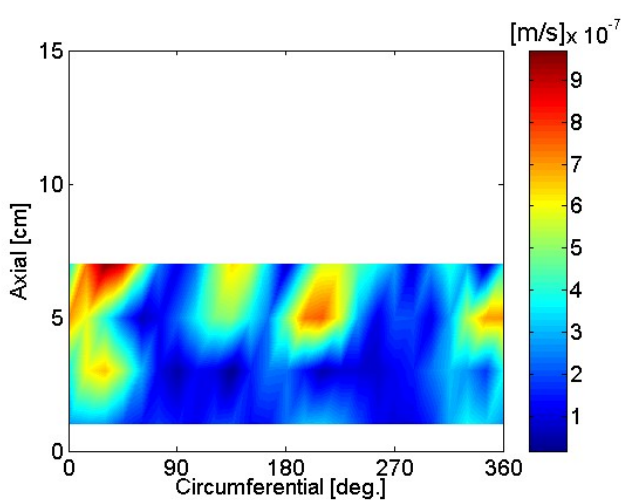

(b)

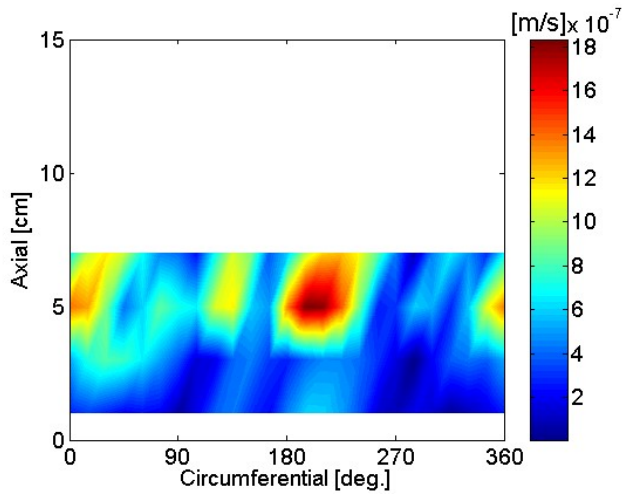

(d)

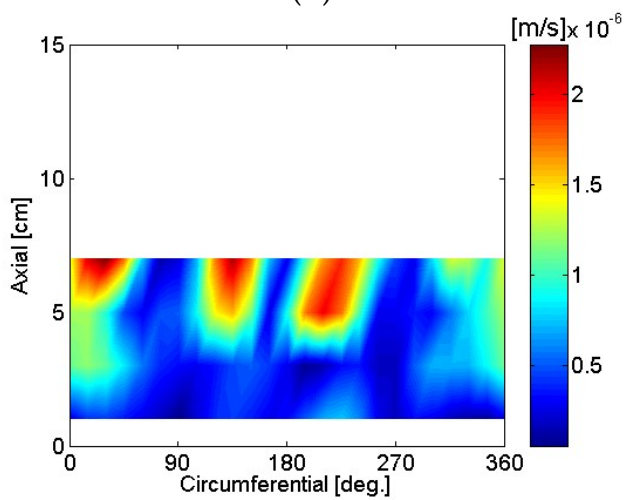

(f)

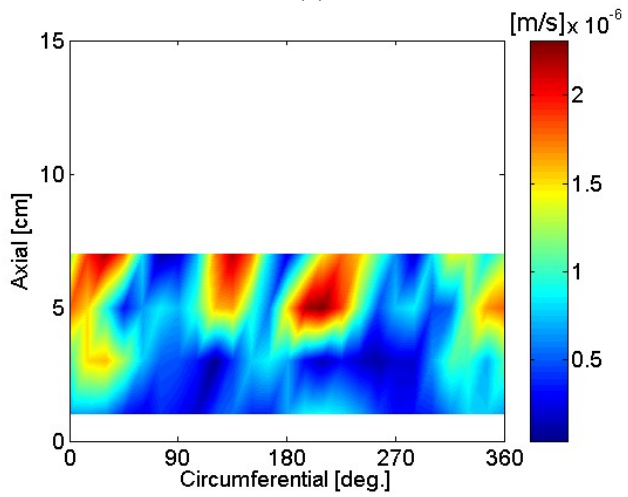

(h)

Figure 22. Particle velocity of the motor, CW: (a) $5120 \mathrm{~Hz}$, current reference; (b) $7172 \mathrm{~Hz}$, current reference; (c) $5120 \mathrm{~Hz}$, moving reference 3; (d) $7172 \mathrm{~Hz}$, moving reference 3; (e) $5120 \mathrm{~Hz}$, moving reference 4; (f) $7172 \mathrm{~Hz}$, moving reference 4; (g) $5120 \mathrm{~Hz}$, auto moving reference; (h) $7172 \mathrm{~Hz}$, auto moving reference. 


\section{Conclusions}

Small motor noise was measured without a reference microphone, and noise and vibration sources for a small DC motor were clearly visualized. As motors become increasingly smaller, the optimal position for a stationary reference microphone may not be accessible due to potential physical interference with scanning microphones. Current measurement for the motor was used as a reference signal, and strategies for small motor noise visualization without using a reference microphone were developed. Scanning microphone measurement signals were combined with current measurements and used as moving reference signals. Motor noise visualization results using current measurement as a reference signal and different moving reference locations were estimated and shown in this study. Also, sound pressure for a motor rotating both CCW and CW was measured over the entire surface to be visualized. Sound pressure and motor current were measured with various capacitance for motor power input. Both sound pressure and motor current were measured for a motor rotating at various speeds, and the transfer functions and ratio of amplitude between sound pressure and motor current were estimated.

Previously, sources of small DC motor noise were accurately visualized over a wide range of frequencies using acoustical holography, with a reference microphone located on top of the motor [6]. Small motor noise was measured and visualized using only current as a reference signal in this research, and it has been shown that it is ideal to use a microphone measurement as a reference rather than current measurement alone. However, noise sources (e.g., $1328 \mathrm{~Hz}$ and $7208 \mathrm{~Hz}$ ) were visualized more clearly by implementing moving references than by using only current measurement as a reference, combining current and scanning microphone measurements close to the motor housing.

Arcs in current measurement for the motor were significantly reduced by connecting a capacitor to the power input of the motor, and motor noise level was reduced by about one $\mathrm{dB}$ with an optimal capacitor. Even though significant differences existed in the frequency domain for a motor rotating CCW as opposed to CW, there was no difference in mean sound pressure level, especially with linear weighting of measurement pressure.

A run-up test of the motor with both sound pressure and current measurement captured motor resonances more clearly than sound pressure measurement alone. The transfer function and amplitude ratio of sound pressure and current reflected the motor internal and housing resonance clearly as well.

The high-frequency component of motor current reduced more rapidly than that of sound pressure, so using motor current measurement as a reference for noise source visualization and estimation was not ideal. When combined with sound pressure measurement, however, current measurement offered a reasonable reference in place of a reference microphone. Such a method for sound visualization would be appropriate for improving the source characterization of very small motors and structures where a reference microphone cannot be placed in an optimal location close to sources.

Conflicts of Interest: The author declares no conflict of interest.

\section{References}

1. Zhu, Z.Q.; Ishak, R.D.; Howe, D. Analysis of cogging torque in brushless machines having nonuniformly distributed stator slots and stepped rotor magnets. IEEE Trans. Magn. 2005, 41, 3910-3912. [CrossRef]

2. Hsiao, C.; Yeh, S.; Hwang, J. A novel cogging torque simulation method for permanent-magnet synchronous machines. Energies 2011, 4, 2166-2179. [CrossRef]

3. Espidola-Lópec, E.; Gomez-Espinosa, A.; Carrillo-Serrano, R.V.; Jáuregui-Correa, J.C. Fourier series learning control for torque ripple minimization in permanent magnet synchronous motors. Appl. Sci. 2016, 6, 254. [CrossRef]

4. Lee, H.J.; Chung, S.U.; Hwang, S.M. Noise source identification of a BLDC motor. J. Mech. Sci. Technol. 2008, 22, 708-713. [CrossRef]

5. Study of DC Permanent Magnet Motor Noise Related to the Line Current. Available online: https:/ / docs.lib. purdue.edu/ecetr/174/ (accessed on 12 May 2018). 
6. Cho, Y.T. Characterizing sources of small DC motor noise and vibration. Micromachines 2018, 9, 84. [CrossRef]

7. Kompella, M.S.; Davies, P.; Bernhard, R.J.; Ufford, D.A. A technique to determine the number of incoherent sources contributing to the response of a system. Mech. Syst. Signal Process. 1994, 8, 363-380. [CrossRef]

8. Kwon, H.S.; Kim, Y.J.; Bolton, J.S. Compensation for source non-stationarity in multi-reference, scan-based nearfield acoustical holography. J. Acoust. Soc. Am. 2003, 113, 360-368. [CrossRef] [PubMed]

9. Cho, Y.T.; Bolton, J.S.; Kwon, H.S.; Kim, Y.J. Holographic visualization of multi-component sources by using reference measurements only. Noise Control Eng. J. 2007, 55, 257-265. [CrossRef]

10. Williams, E.G. Fourier Acoustics: Sound Radiation and Nearfield Acoustical Holography; Academic Press: London, UK, 1999; ISBN 0-12-753960-3.

11. Weinreich, G.; Arnold, E.B. Method for measuring acoustic radiation fields. J. Acoust. Soc. Am. 1980, 68, 404-411. [CrossRef]

12. Williams, E.G.; Dardy, H.D.; Washburn, K.B. Generalized nearfield acoustic holography for cylindrical geometry: Theory and experiment. J. Acoust. Soc. Am. 1987, 81, 389-407. [CrossRef]

13. Steiner, R.; Hald, J. Near-field acoustical holography without the errors and limitations caused by the use of spatial DFT. In Proceedings of the ICSV6, Copenhagen, Denmark, 5-8 July 1999; pp. 83-89.

14. Hald, J. Patch near-field acoustical holography using a new statistically optimal method. In Proceedings of the INTER-NOISE 2003, Jeju, Korea, 25-28 August 2004; pp. 2203-2210.

15. Cho, Y.T.; Bolton, J.S.; Hald, J. Source visualization by using statistically optimized near-field acoustical holography in cylindrical coordinates. J. Acoust. Soc. Am. 2005, 118, 2355-2364. [CrossRef]

16. Cho, Y.T.; Bolton, J.S. Visualization of automotive power seat slide motor noise. In Proceedings of the NOISE-CON 2014, Fort Lauderdale, FL, USA, 8-10 September 2014; pp. 332-339.

17. Cho, Y.T. Noise source visualization using a digital voice recorder and low-cost sensors. Sensors 2018, 18, 1076. [CrossRef] [PubMed]

(C) 2018 by the author. Licensee MDPI, Basel, Switzerland. This article is an open access article distributed under the terms and conditions of the Creative Commons Attribution (CC BY) license (http://creativecommons.org/licenses/by/4.0/). 